\title{
Dynamic Evolutionary Games and Coordination of Multiple Recycling Channels considering Online Recovery Platform
}

\author{
Meihong Zhu, ${ }^{1,2}$ Xiao Li $\mathbb{D}^{\circ},{ }^{2}$ Liqing Zhu, ${ }^{1}$ Xueli Zhan $\mathbb{D}^{1,3}$ and Junhai Ma ${ }^{1}{ }^{1}$ \\ ${ }^{1}$ College of Management and Economics, Tianjin University, Tianjin 300072, China \\ ${ }^{2}$ Zhejiang University of Water Resources and Electric Power, Zhejiang 310018, China \\ ${ }^{3}$ School of Economics, Beijing Wuzi University, Beijing 101149, China \\ Correspondence should be addressed to Xiao Li; xiaoli20180828@126.com and Xueli Zhan; xuelz20163205@126.com
}

Received 15 March 2021; Accepted 25 July 2021; Published 3 August 2021

Academic Editor: Sundarapandian Vaidyanathan

Copyright $\odot 2021$ Meihong Zhu et al. This is an open access article distributed under the Creative Commons Attribution License, which permits unrestricted use, distribution, and reproduction in any medium, provided the original work is properly cited.

Nowadays, with a great number of household electrical appliances being discarded in every corner of the world every day, household electrical appliances recycling is attracting more attention. In this paper, we build a closed-loop supply chain that consists of a manufacturer and a third-party recycler based on the development of "Internet Plus" recovery platform. We thoroughly analyze the model and its evolution by chaos theory, complex dynamics theory, and numerical simulation and introduce the adaptive method to control the chaos of the system. We find that as the manufacturer increases the retail price, the stable area of the market becomes smaller. At the same time, when the manufacturers direct recycle price or the price adjustment range of the products recycled from the third party exceeds a certain threshold, all the recycle prices in the whole market will fluctuate, thus causing market chaos. Among them, as an adjustment decision method, delay strategy reduces the volatility of recycle price and makes it return to a stable state, which is an effective method to control system disorder. In addition, the third-party recycler will change the optimal subsidy model according to the government's price subsidy level, while the manufacturer always prefers the price subsidy model.

\section{Introduction}

Since governments worldwide are giving increasing attention to global environmental issues, more and more managers and scholars also pay attention to the recycling problem. At present, many corporations possess recycling sectors by themselves or cooperate with third-party offline recyclers that collect remanufactured products. Recycling products is beneficial to enterprise development and can help consumers save money, which makes a significant contribution to sustainable development. Thus, the research of the online recovery platform is becoming a hot issue.

In recent years, the speed of electronic product replacement is accelerating. As the biggest developing country globally, China is a significant producer and consumer of electrical and electronic products. According to the Data from the National Bureau of Statistics, the total retail sales of major commodities in China in 2019 were 3.6428 trillion yuan, among which the total retail sales of household appliances and audio and video equipment reached 913.9 billion yuan, accounting for about $2.5 \%$ of the total retail sales, an increase of about $0.17 \%$ compared with 2018 . The retail sales of household appliances and audio and video equipment grew 1.7 percentage points faster on average than the retail sales of consumer goods above designated quotas. Among them, the air conditioning market's retail sales share reached $59.2 \%$, and the retail sales share reached $46.9 \%$, both significantly higher than last year. Refrigerator market sales of 99.5 billion yuan, a year-on-year growth of $0.45 \%$. But now consumer electronics are becoming saturated. Meanwhile, household appliances, as durable consumer goods, are becoming more and more popular in Chinese households [1, 2]. From the above data, the output of most household electrical appliances has achieved a small increase, which means that the market of used electrical and electronic products has enormous potential to realize rapid development.

On the basis of existing research of closed-loop supply chain, reverse supply chain, and the development of the waste 
recycling market, Savaskan et al. [3] pointed out that the recycling channels for waste products can be classified into three categories: recycling by manufacturers, recycling by retailers, and recycling by third-parties. Besides, with the rapid development of information technology, logistics and distribution systems, and Internet technologies, new ways of recycling have also emerged in the used electronic products recycling market. In 2015, the State Council reviewed and promulgated several plans, which indicated that, to comply with the development trend of the "Internet plus" in the world, "Internet plus" refers to the application of the internet and other information technology in conventional industries. We need to fully take the advantage of scale and Internet, promote the expansion of the Internet from the consumer field to the production field, accelerate the improvement of the level of industrial development, and enhance the innovative capacity of the waste recycling industry [4]. Under this policy, the "Internet + Recycling" platform, a consumer-centric waste recovery e-commerce system, has rapidly emerged, as well as the "Love Recovery" platform, the Gome recycling platform, the Suning recycling platform, and the Jingdong recycling platform, for instance. Online recovery platform reduces the transaction costs, improves the information asymmetry between the buyers and sellers of used products, and improves the efficiency of recycling, so it has become a popular recycling channel, through which consumers are keen to resell used products [5]. In this paper, we take the "Love Recovery" network recycling platform as an example. As described by Dou [6], this platform provides several recycling ways for consumers to choose: first, consumers can ask for on-site recycling services and select a service site on the network; second, consumers can return used goods for recycling by going directly to the offline stores; besides, consumers can send back the used products to the platform. After professional inspection, some products are repaired and refurbished and go to the secondary market, and the others that cannot be reused are taken away by environmental protection companies. Meanwhile, many manufacturing companies not only recycle used products through traditional channels such as third-party institutions and retail sales, but also create their own recycling channels in virtue of Internet technologies to form a multichannel recycling model. We take Changhong as an example. It established Changhong Gerun Recycling Resources Limited Liability Company, which has 2 million/year processing capacity for five major used household appliances categories: televisions, refrigerators, air conditioners, washing machines, and computers. It also built a "sky-to-ground" recycling network, which includes the "ground nets"-the self-built outlets and franchise recyclers in each region-and the "sky nets"- telephone, network platform, and so on-a typical O2O mode. As illustrated by Cattani et al. [7], relying on advanced information intelligence technology, they develop waste electronic smart recycling ATMs used in the community and build a leading intelligent recycling platform in China.

Based on the background, this paper makes contributions in the field of multiple recycling channels. First of all, considering the emergence of new recycling methods in the rapid development of Internet technology and combining with the online recycling of the third party, we constructed the recycling amount function and profit function of the manufacturer and the third-party recycler. Then, because the decision-making process is dynamic, we introduce the nonlinear dynamics theory into the system and use the bifurcation diagram and stable domain diagram to analyze and express the chaotic phenomenon in the model. Finally, we analyze the effect of the delay strategy on chaos control.

This paper is organized as follows: In Section 3, the assumptions are listed, and the model of the recycling system is built. In Section 4, the model is solved, and the equilibrium points are calculated. Nonlinear dynamics theory is also introduced in this part. In Section 5, the numerical simulation is used to express the chaos of the model by bifurcation diagram and stability domain diagram, and the effects of relevant parameters on the model are also studied. In Section 6, the effective control of chaos is adopted in this supply chain system. Section 7 discusses the extended model. The conclusions are presented in the last section.

\section{Literature Review}

The closed-loop supply chain has been paid much attention these years, since the recycling process is beneficial to the economic viability and environmental sustainability [7]. There is plenty of available literature we can find. The structure of the supply chain is so important that lots of scholars have researched it. Also relying on a closed-loop supply chain, a game involving an online direct sale channel between the manufacturer and the traditional retailer has been established and analyzed [8]. Sun and $\mathrm{Ma}$ [9] studied dynamic pricing games in dual-channel supply chains with risk-averse behaviors and incomplete information. Another closed-loop supply chain consisting of a positive chain that includes an online channel and a retailer channel has been investigated, where government subsidies consumers who return the waste products and purchase new products through retailers [10]. As a result, profits of manufacturers and retailers increase, but the impact of online channel providers on profits is not obvious. Strategies of players in a supply chain under five modes (centralized decision model, Nash equilibrium decentralized decision-making model, manufacturer leadership model, retailer leadership model, and third-party leadership Strategic Research on Models) have been researched through the dual recycling channels (third-party recycling channel and manufacturer's online recovery channel) [11]. On the basis of considering green manufacturers to obtain quality information in a closed-loop supply chain, Hong et al. studied quality information disclosure strategies [12]. Zhang and Meng adopted the Stackelberg game and two-level planning methods to establish an electronic closed-loop supply chain value cocreation model that considers the cross-shareholding of manufacturers and retailers [13]. Based on existing literature, collectors who collect used products can be the manufacturer, the retailer, and the third-party collector. In the above literature, the research mainly focuses on the closed-loop supply chain composed of manufacturers, retailers, or other third-party recycling institutions, but the members involved in the supply chain are slightly one-sided. 
At the same time, the supply chain structure relationship is not reasonable. Therefore, this paper constructs a closedloop supply chain consisting of a manufacturer, a third-party offline recycler, and a third-party online recycler to form a three-layer structure relationship and explain the recycling process more reasonably.

Pricing also has been paid much attention to the relevant literature. Wood et al. developed a descriptive model of locking pricing practices by interviewing the practices, conventions, and perspectives of decision-makers from five online fashion retailers in pricing [14]. Ma et al. [15] found the impact of pricing time on profitability and stability. A closedloop supply chain is constructed and analyzed under four different decision structures, in which the retailer collects used products in two ways [16]. Ma et al. [17] considered the level and historical price discount sensitivity when establishing the price sensitive demand function. The effects of recycling and product quality level on pricing decisions in a two-echelon closed-loop supply chain were also analyzed [18]. The effect of the technology licensing on remanufacturing in a two-period closed-loop supply chain was analyzed, where a manufacturer produced new and remanufactured products, and a remanufacturer collected used products and produced remanufactured products at the same time in Hong's research [19]. A closed-loop supply chain was analyzed, in which supply chain members made centralized decisions and three decentralized collection modes, and the dynamic pricing strategies were also studied in this research in Sun et al. paper [20]. The price decision will be affected by the supply chain buyback contracts and government subsidies [21,22]. In addition, the demand fluctuation caused by the promotion price policy will also affect the integrated inventory control system [23]. Sander found that if quality and cost are negatively correlated, the company can restore competitive pricing by privately setting its quality and cost [24]. Modak et al. [25] consider three possible collection activities of used product for recycling, viz, retailer led collection, manufacturer led collection, and third-party-led collection and analyze the optimal pricing, and government organizations provide incentives to the manufacturers for adopting green technologies [26].

This paper is also related with literature about government intervention. Previous scholars have done a lot of studies on government intervention. Li et al. [27] examined the optimal decision of the supply chain and the effective environmental governance strategy of the government. Based on wholesale price and revenue sharing contracts under cap-and-trade regulation, Ji et al. [28] explored the production decision, as well as the government cap setting. Raz and Ovchinnikov [29] analyzed how the government can coordinate the supply through using rebate and subsidy. $\mathrm{Li}$ and $\mathrm{Li}$ [30] studied the interaction between the government's subsidy regulations and the firms' marketing regimes.

Considering economic viability and environmental sustainability, more and more manufacturers devote to the process of remanufacturing, in which a used product transforms into a "new" product. Meanwhile, scholars are also paying increasing attention to remanufacturing. A two-period closed-loop supply chain was built with a single manufacturer and a single remanufacturer, and their decisions under different cooperative strategies were studied in relevant studies [31]. The pricing decision of the manufacturer and the remanufacturer under different consumers' behaviors were also studied [32]. Besides, a two-period closed-loop supply chain was established to analyze whether the collection of the used products should be outsourced [33]. Additionally, a closed-loop supply chain consisting of a manufacturer, a retailer, and a supplier was investigated considering the dynamic performance of the model [34]. The effect of remanufactured products on new products was also researched [35]. Companies will adopt green technology to reduce environmental pollution [36]. Ata studied the optimal pricing and production tactics for a bi-echelon green supply chain [37]. From the consumer's point of view, consumers will also consider whether the product is a green product, which will also affect the sales price and demand of the product [38-40]. From the above literature, we can know that many scholars have noticed the importance of pricing in the closed-loop supply chain. But most price decisions are set in a static model. In this paper, the dynamic model is used to study the price.

Nonlinear dynamics is an effective theory and adopted widely. Lots of scholars combine supply chain with nonlinear dynamics theory. The recycling network of color TV recycling market is studied [39]. Feng et al. [40] studied the game between four nonlinear hybrid oligopolies. They introduced nonlinear dynamics theory into the system and analyzed the complexity of the system. In the end, they adopted the method of delay control to control the chaos. A dual-channel closed-loop supply chain was researched under government intervention in order to analyze relevant parameters' effect on the stability and complexity of the system [41]. They also adopted the delay feedback control method to control the system. A closed-loop supply chain was investigated and presented by dynamic phenomena; the stability and complexity of the system were also analyzed [42]. In this model, the retailer sells and collects products, and the manufacturer produces and recycles products. Through relevant researches, scholars have proved the feasibility of combining nonlinear dynamics with closed-loop supply chain. In this paper, the dynamic system of a new closed-loop supply chain structure is studied and analyzed by using the theory of nonlinear dynamics. In addition, different from the static game model research [43], the literature [44-46] also combines the theory of complex dynamic systems to study the closedloop supply chain problem. Similarly, based on the evolutionary game theory, Su et al. [47] established the trilateral-game payoff matrix, build up the replicator dynamic equations, and discussed possible evolutionary stable states, and based on the theoretical framework of information entropy and complexity, Su et al. [48] discussed the APQSIS agents' equilibrium strategies.

Based on the studies mentioned above, most scholars used static games in relevant works. However, in reality, the decision process of supply chain members is dynamic. Members in the supply chain cannot have a good knowledge of all information about the market or adjust their decisions at any time. Therefore, the supply chain might have more 
complex characteristics. Stability is an important focus for both nonlinear dynamic system and supply chain management. Recyclers in the product market will engage in healthy competition. To fill these gaps, we start by characterizing how the price strategy of supply chain members changes under different recycling channels based on nonlinear dynamics theory. Subsequently, in the collecting system, we investigate the dynamic changes of the system for used products on pricing decisions.

\section{Model Description and Assumption}

The background of the model is given in this section. The symbols and assumptions used in the following section are described as well.

3.1. Model Description. The closed-loop supply chain in this paper is composed of a manufacturer, a third-party online recycler, a third-party offline recycler, and consumers. Consumers can choose to return used products through the third-party online recycler, the third-party offline recycler, or the manufacturer. Besides, the third-party online recycler and the third-party offline recycler sale used products they collect from consumers to the manufacturer. At the end, the manufacturer remanufactures used products and directly sales remanufactured products to consumers. The model is shown in Figure 1.

3.2. Symbols and Assumptions. Relevant symbols involved are given as follows:

$D_{d}$ : recycling quantity of the manufacturer

$D_{t}$ : recycling quantity of the third-party offline recycler

$D_{r}$ : recycling quantity of the third-party online recycler

$p_{d}$ : recycling price of used products collected by the manufacturer to the consumer

$p_{t}$ : recycling price of used products collected by the third-party offline recycler

$p_{r}$ : recycling price of used products collected by the third-party online recycler

$p$ : retailer price of remanufactured products

$\omega$ : recycling price of used products collected by the manufacturer to the third-party

$c$ : remanufacturing cost of used products

$b_{1}$ : consumers' sensitivity coefficient to the price of third-party online recyclers' recycling channel

$b_{2}$ : consumers' sensitivity coefficient to the price of third-party offline recyclers' recycling channel

$b_{3}$ : consumers' sensitivity coefficient to the price of manufacturer' recycling channel

a: basic market size of used products market

$\theta_{1}$ : consumer dependence on the online channel

$\theta_{2}$ : consumer dependence on third-party offline recyclers' recycling channel

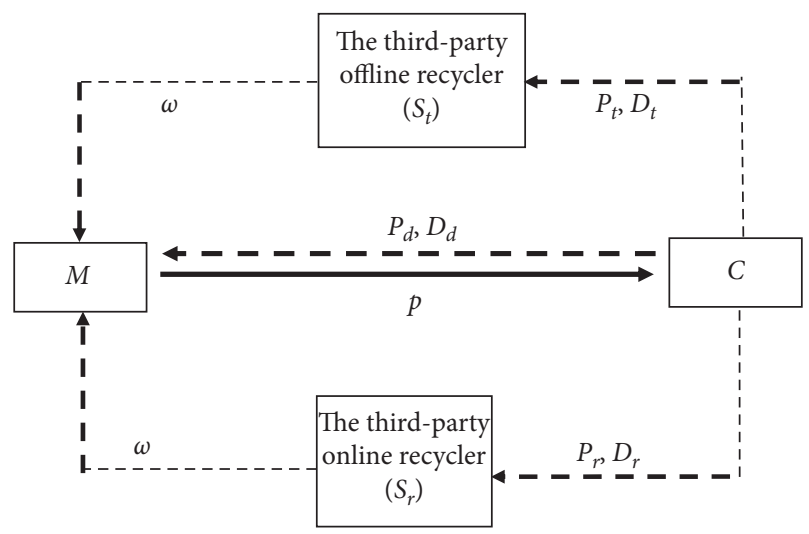

FIGURE 1: Recycling supply chain model.

$r_{1}$ : price cross influence coefficient between the third-party online recycler and third-party offline recycler

$r_{2}$ : price cross influence coefficient between the manufacturer and third-party online recycler

$r_{3}$ : price cross influence coefficient between the manufacturer and third-party offline recycler

$\pi_{r}$ : third-party offline recycler's profit

$\pi_{t}$ : third-party online recycler's profit

$\pi_{m}$ : manufacturer's profit

$S_{r}$ : other operating costs of the third-party online recycler

$S_{t}$ : other operating costs of the third-party entity recycler

$S_{d}$ : other operating costs of the manufacturer

In order to simplify the analysis, we make these assumptions as follows:

(i) When the quality level of the remanufactured product reaches the qualified standard, it can be put back into the market for sale. Here, we assume that the manufacturer's remanufactured products are qualified products. In practice, manufacturing companies do the same, such as refurbished machines sold by Apple.

(ii) The recovery capability of the three channels and the manufacturing capability of the manufacturer can meet the demand in the market. The market is large enough to consume enough products.

(iii) Recycling quantity function is linear, and recycling quantity is related to price. Factors such as environment, service, and consumption level are not considered [49-51].

(iv) Manufacturers and the third-party recyclers are independent decision-makers, and the goal of decision-making is to maximize their own profits. Because of the constraints of the market conditions, they cannot fully grasp the behaviors and decisions of other decision-makers and take a limited rational method to make decisions. 


\section{Model Construction and Analysis}

In this section, we construct the corresponding dynamic model. The players make decisions based on the principle of bounded rationality. Also, the optimal solutions are derived.

4.1. Model Construction. The functions of recycling quantity of the third-party recyclers and manufacturer are shown as follows:

$$
\left\{\begin{array}{l}
D_{r}=\theta_{1} a+b_{1} p_{r}-r_{1}\left(p_{t}-p_{r}\right)-r_{2}\left(p_{d}-p_{r}\right), \\
D_{t}=\theta_{2} a+b_{2} p_{t}-r_{1}\left(p_{r}-p_{t}\right)-r_{3}\left(p_{d}-p_{t}\right), \\
D_{d}=\left(1-\theta_{1}-\theta_{2}\right) a+b_{3} p_{d}-r_{2}\left(p_{r}-p_{d}\right)-r_{3}\left(p_{t}-p_{d}\right) .
\end{array}\right.
$$

In this model, there are three channels, so we also assume $0 \leq \theta_{1}+\theta_{2} \leq 1$. And because there is no study focusing on difference and degree of the price sensitivity coefficient between recycling channels, we assume that price sensitivity coefficients and price cross influence coefficients are invariable, that is, $b_{1}=b_{2}=b_{3}$ and $r_{1}=r_{2}=r_{3}$. According to the actual situation, in each recycling channel, the price of one channel has greater impact on the price of other channels, that is, $b>r$. In this study, we can simplify the functions as follows:

$$
\left\{\begin{array}{l}
D_{r}=\theta_{1} a+b p_{r}-r\left(p_{t}-p_{r}\right)-r\left(p_{d}-p_{r}\right), \\
D_{t}=\theta_{2} a+b p_{t}-r\left(p_{r}-p_{t}\right)-r\left(p_{d}-p_{t}\right), \\
D_{d}=\left(1-\theta_{1}-\theta_{2}\right) a+b p_{d}-r\left(p_{r}-p_{d}\right)-r\left(p_{t}-p_{d}\right) .
\end{array}\right.
$$

The profit model can be given as follows:

$$
\begin{gathered}
\pi_{r}=\left(\omega-p_{r}\right) D_{r}-S_{r}, \\
\pi_{t}=\left(\omega-p_{t}\right) D_{t}-S_{t}, \\
\pi_{m}=\left(p-p_{d}-c\right) D_{d}+(p-\omega-c)\left(D_{r}+D_{t}\right)-S_{d} .
\end{gathered}
$$

In the profit function, the manufacturer's profit can be divided into two parts, which are recycling products from the third-party recycler and recycling products by collecting directly from consumers. Since the manufacturer requires consumers to pay a certain amount of cost for recycling, consumers are less dependent on the manufacturer' recycling channels even if the recycling cost is higher. But the high recycling price will weaken the price competitiveness of other channels and also cause vicious price competition, which violates the original intention of manufacturers, that is, expanding the market by using multiple recycling channel.

4.2. Complexity Analysis of Market Stackelberg Game Behavior. We put formula (2) into formulas (3)-(5). Then, players' profit in supply chain can be shown as follows:

$$
\begin{aligned}
E\left(\pi_{r}\right)= & \left(\omega-p_{r}\right)\left[\theta_{1} a+b p_{r}-r\left(p_{t}-p_{r}\right)-r\left(p_{d}-p_{r}\right)\right]-S_{r}, \\
E\left(\pi_{t}\right)= & \left(\omega-p_{t}\right)\left[\theta_{2} a+b p_{t}-r\left(p_{r}-p_{t}\right)-r\left(p_{d}-p_{t}\right)\right]-S_{t}, \\
E\left(\pi_{m}\right)= & \left(p-p_{d}-c\right)\left[\left(1-\theta_{1}-\theta_{2}\right) a+b p_{d}-r\left(p_{r}-p_{d}\right)-r\left(p_{t}-p_{d}\right)\right] \\
& +(p-\omega-c)\left[\left(\theta_{1}+\theta_{2}\right) a+(b+r)\left(p_{r}+p_{t}\right)-2 r p_{d}\right]-S_{d} .
\end{aligned}
$$

In this model, the third-party recycler and the manufacturer form Stackelberg game, so backward induction is used to analyze the model, and we consider the third-party recyclers first.

The game process of the paper is organized as follows. The manufacturer makes simultaneous decisions based on its recycling price and wholesale price firstly. The thirdparty online and offline recyclers make recycling price decisions according to the manufacturer. This study mainly aims to analyzing the complexity on the whole system. According to formulas (6) and (7), we can derive the following formula:

$$
\left\{\begin{array}{l}
\frac{\partial \pi_{r}}{\partial p_{r}}=-\theta_{1} a+r\left(p_{t}+p_{d}\right)+\omega(b+2 r)-2 p_{r}(b+2 r), \\
\frac{\partial \pi_{t}}{\partial p_{t}}=-\theta_{2} a+r\left(p_{r}+p_{d}\right)+\omega(b+2 r)-2 p_{t}(b+2 r) .
\end{array}\right.
$$

According to formula (9), when $\left(\partial \pi_{r} / \partial p_{r}\right)=0,\left(\partial \pi_{t} / \partial p_{t}\right)=0$, we obtain the optimal recovery price of the third-party online recycler and the thirdparty offline recycler, which is the optimal marginal profit function of the third-party recyclers. 


$$
\left\{\begin{array}{l}
p_{r}=\frac{-\theta_{1} a+r\left(p_{t}+p_{d}\right)+\omega(b+2 r)}{2(b+2 r)}, \\
p_{t}=\frac{-\theta_{2} a+r\left(p_{r}+p_{d}\right)+\omega(b+2 r)}{2(b+2 r)} .
\end{array}\right.
$$

According to formula (10), the optimal pricing expression of the third-party recyclers can be shown as follows:

$$
\left\{\begin{array}{l}
p_{r}^{*}=\frac{2 b^{2} \omega+b\left(2 p_{d} r-2 a \theta_{1}+9 r \omega\right)+r\left(-a\left(4 \theta_{1}+\theta_{2}\right)+5 r\left(p_{d}+2 \omega\right)\right)}{(2 b+5 r)(2 b+3 r)} \\
p_{t}^{*}=\frac{2 b^{2} \omega+b\left(2 p_{d} r-2 a \theta_{2}+9 r \omega\right)+r\left(-a\left(4 \theta_{2}+\theta_{1}\right)+5 r\left(p_{d}+2 \omega\right)\right)}{(2 b+5 r)(2 b+3 r)}
\end{array}\right.
$$

Substitute formula (11) into formula (8). We find that Hessian matrix is negative, which means that manufacturer's profit model is strictly a concave function.

$$
\begin{aligned}
& H^{1}=-\frac{2\left(2 b^{2}+7 b r+4 r^{2}\right)}{2 b+3 r}<0, \\
& H^{2}=\frac{8 b\left(b^{2}+5 b r+6 r^{2}\right)}{2 b+3 r}>0 .
\end{aligned}
$$

$$
\begin{aligned}
& \left\{\begin{array}{l}
\frac{\partial \pi_{m}}{\partial p_{d}}=\frac{\left(\begin{array}{c}
\alpha\left(c-p+p_{d}\right)\left(2 b^{2}+7 b r+4 r^{2}\right)\left(-1+\theta_{1}+\theta_{2}\right)+2 r(b+2 r)(c-p+\omega)+ \\
\alpha\left(-1+\theta_{1}+\theta_{2}\right)\left(2 b^{2} p_{d}+b r\left(7 p_{d}-2 \omega\right)+r\left(4 p_{d} r+\alpha\left(\theta_{1}+\theta_{2}\right)-4 r \omega\right)\right)
\end{array}\right)}{2 b+3 r}, \\
\frac{\partial \pi_{m}}{\partial \omega}=\frac{\left((b+2 r)\left(2 p_{d} r-2 \alpha\left(c-p+p_{d}\right) r\left(-1+\theta_{1}+\theta_{2}\right)-\alpha\left(\theta_{1}+\theta_{2}\right)-2(b+r) \omega-2(b+r)(c-p+\omega)\right)\right)}{2 b+3 r} .
\end{array}\right. \\
& +3 r
\end{aligned}
$$

According to formula (13), when $\left(\partial \pi_{m} / \partial p_{d}\right)=0,\left(\partial \pi_{m} / \partial \omega\right)=0$, the Nash equilibrium solution of this game can be obtained, which is the optimal marginal profit function of recycling price of used products collected by manufacturer to consumer, $p_{d}$ and recycling price of used products collected by manufacturer to the third-party, $\omega$ and the specific expression can be seen in Appendix.

Assuming that pricing game between the manufacturer and the third-party is not instantaneous, there is a repeated game pricing process. In repeated game stage, any participant has the operating goal of maximizing the profit and cannot fully grasp market information of product and competitors' business information. So, each participant is not a fully rational decision maker. Combining these conditions, we assume that the three participants in this model are both limited rational decision-makers, who cannot predict the market demand information accurately or completely control their pricing behavior. In the periodic
We make the first derivative of the profit function of manufacturer equal to zero, and the functions are as follows: repeating game, the manufacturer dynamically adjusts the price. Based on the marginal profit of the decision of the previous period, the manufacturer makes current decision on the basis of forecast information. That is, if the manufacturer's marginal profit is positive in the period $t$, the strategy is to be continue in the $t+1$ period. On the other hand, if the manufacturer accounts for the negative marginal profit of the period $t, p_{d}$ and $\omega$ should be adjusted in the period $t+1$. The dynamic adjustment model of repeated game is

$$
p_{i}(t+1)=p_{i}(t)+\beta_{i} p_{i}(t) \frac{\partial \pi_{i}(t)}{\partial p_{i}(t)}
$$

As a bounded rational economic offline recycler, the recycling players have long and prosperous business experience. When they make price decision of period $t+1$, they should take the profit of the period $t$ into consideration. The bounded rationality analysis will make player's decision more rational. $\beta_{i}$ represents price adjustment speed of 
participants. According to formula (15), the pricing expression of the manufacturer in the repeated game can be obtained.

$$
\begin{gathered}
p_{d}(t+1)=p_{d}(t)+\beta_{1} p_{d}(t) \frac{\partial \pi_{m}(t)}{\partial p_{d}(t)}, \\
\omega(t+1)=\omega(t)+\beta_{2} \omega(t) \frac{\partial \pi_{m}(t)}{\partial \omega(t)} .
\end{gathered}
$$

\section{Numerical Simulations}

In the Section 4, we show the manufacturer's game process, in which the manufacturer adjusts his pricing strategy on the basis of the marginal profit of the previous period. If the marginal profit of the previous period is positive, the manufacturer will keep the strategy of the last period in the next period. Even if the third-party offline and online recycler raise their price to increase recycling quantity in the next period, the manufacturer will still not adjust strategy and keep the belief that his profit will be maximized. On the other hand, if the manufacturer's marginal profit is negative, he will not adopt the strategy of the last period, because the strategy has a bad impact on profit. When the manufacturer adjusts parameters in the next period, the whole system stability will be affected.

The changes of $\beta_{1}$ and $\beta_{2}$ can affect system's stability in the process of repeated game. In order to describe the dynamic change process accurately, we set some parameters for numerical simulation analysis. In this paper, we set $a=10$, $c=5, \theta_{1}=0.65, \theta_{2}=0.2, b=0.6, r=0.4, s_{r}=1, s_{t}=0.1$, $s_{d}=300, p=30$, and then we can obtain

$$
\begin{aligned}
p_{d}(t+1) & =p_{d}(t)+\beta_{1} p_{d}(t)\left(33.708-3.8 p_{d}+1.167 \omega\right), \\
\omega(t+1) & \left.=\omega(t)+\beta_{2} \omega(t)\left(6.708+1.167 p_{d}-2.33 \omega\right)\right) .
\end{aligned}
$$

Let $p_{d}(t+1)=p_{d}(t)$ and $\omega(t+1)=\omega(t)$, and we can get $p_{d}^{*}=11.52, \omega^{*}=8.64, p_{t}^{*}=5.89, p_{r}^{*}=4.48$. According to the Jury stability criterion, we can get the stable region of $\beta_{1}$ and $\beta_{2}$ as follows.

In the repeated game process of the adjustment, due to limited information, the manufacturer constantly adjusts the pricing strategy to get closer to the optimal price of profit maximization. If the speed of price changing is too fast, the system will become instable and enter the chaotic state. In Figure 2, we draw the stable region with the changes of $\beta_{1}$ and $\beta_{2}$, then the reasonable ranges of parameters $\beta_{1}$ and $\beta_{2}$ can be got. In order to describe the effect of the speed of the price adjustment on system's stability, we draw the bifurcation diagram of $p_{d}$ and $\omega$ when $\beta_{1}=0.0085$ and $\beta_{2}=0.015$ respectively.

In Figures 3 and 4 , we describe the changes of $p_{d}$ and $\omega$ with $\beta_{2}$ and $\beta_{1}$. The system is steady at the beginning. With the increasing of $\beta_{1}$ and $\beta_{2}$, the system becomes periodic bifurcation and enters chaotic state at the end. Therefore, we can observe that, with the increase of price in recycling channel, the system is losing stability.

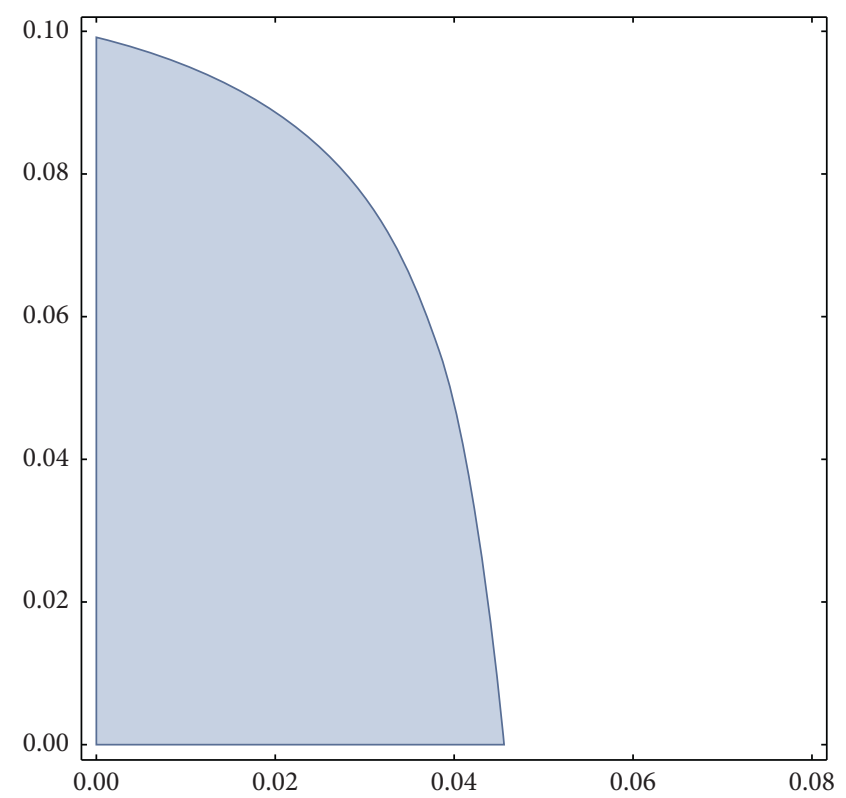

FIgURE 2: The stable region with the change of $\beta_{1}$ and $\beta_{2}$.

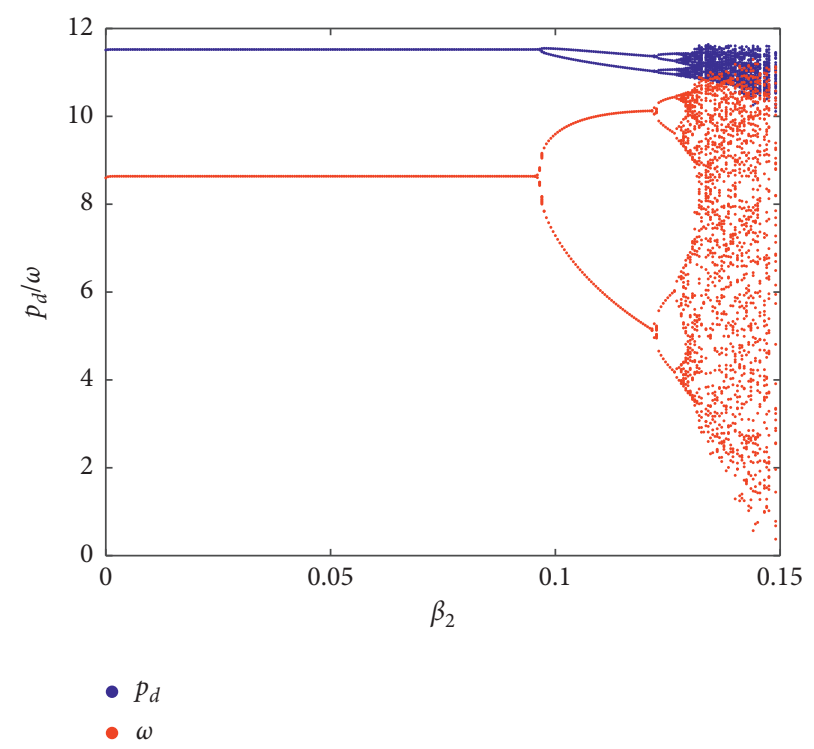

FIgURE 3: Bifurcation diagram of $p_{d}$ and $\omega$ when $\beta_{1}=0.0085$.

In Figures 5 and 6, we describe the changes of $p_{r}$ and $p_{t}$ with $\beta_{2}$ and $\beta_{1}$. The third-party offline recycler and the third-party online recycler follow the manufacturer. When the manufacturer's price fluctuates, the price of the third-party offline recycler and the third-party online recycler also fluctuates, and the vicious cycle will lead to chaos.

In Figures 7 and 8, we describe the changes of profits with $\beta_{2}$ and $\beta_{1}$. When $\beta_{2}$ and $\beta_{1}$ are small, the profits from the three channels are stable. When the manufacturer's price fluctuates, the price of the third-party offline recycler and the third-party online recycler also fluctuates. This affects the profits of the three recycling channels, making their respective profits chaotic. 


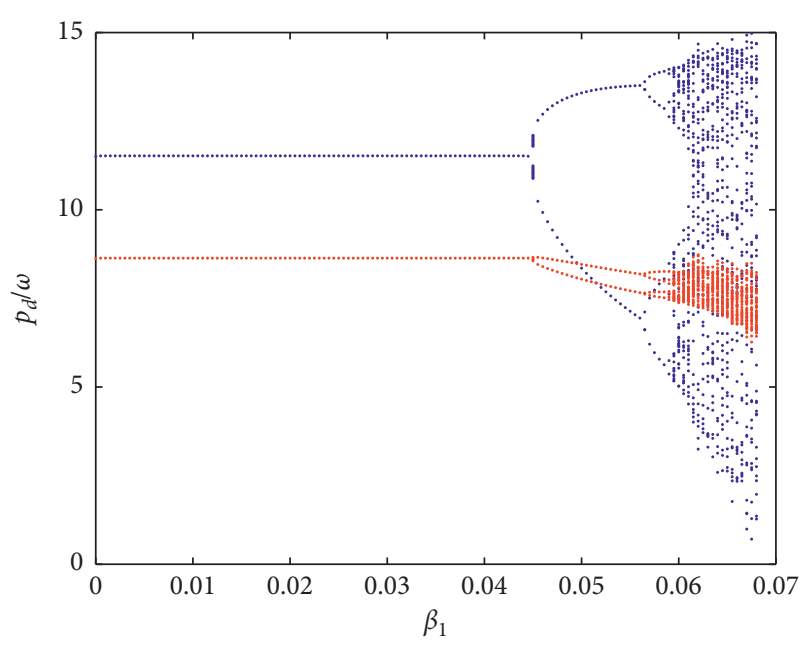

- $p_{d}$

- $\omega$

FIgURE 4: Bifurcation diagram of $p_{d}$ and $\omega$ when $\beta_{2}=0.015$.

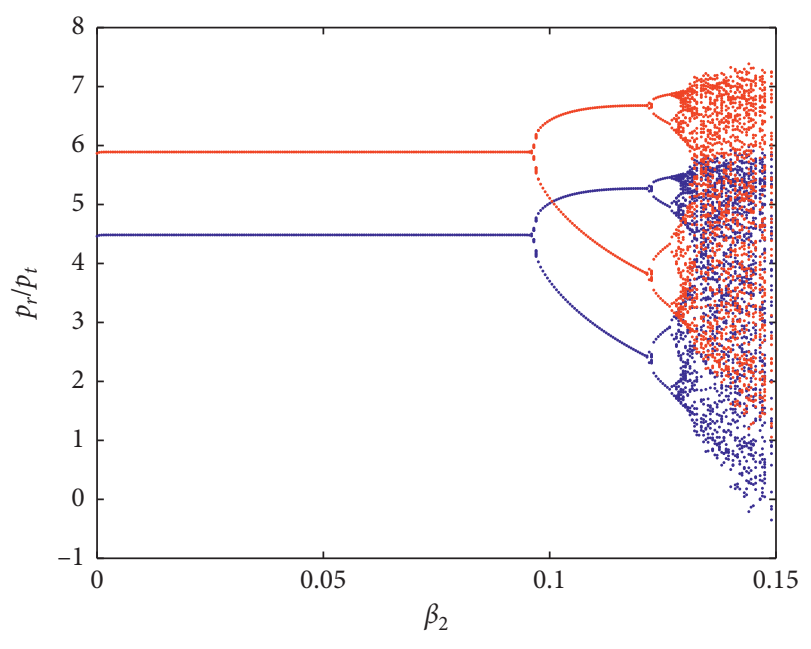

- $p_{r}$

- $p_{t}$

Figure 5: Bifurcation diagram of $p_{r}$ and $p_{t}$ when $\beta_{1}=0.0085$.

Figures 3-8 show how the market changes during the price adjustment process. In summary, it is not difficult to see that price chaos will cause short-term irregular fluctuations in the market economy system. This is caused by the bounded rationality of decision-makers within the system. Therefore, chaotic research can effectively reflect the overall changes in the market economy and help companies make timely decisions.

Combining Figures 5 and 6, we can see from Figures 7 and 8 that the excessive adjustment speed of the system will affect the recovery price of the product, thus affecting the profit of each member of the system. When the recovery price enters into a chaotic state, the whole market will become disordered, which will have a certain impact on the decision-making of each member in the recovery system.

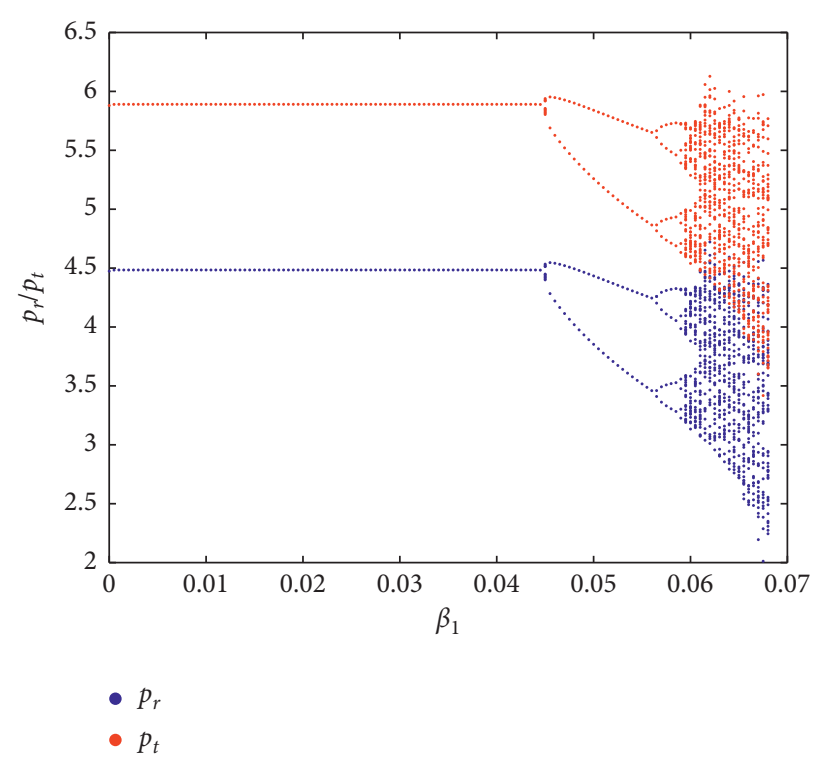

FIgURE 6: Bifurcation diagram of $p_{r}$ and $p_{t}$ when $\beta_{2}=0.015$.

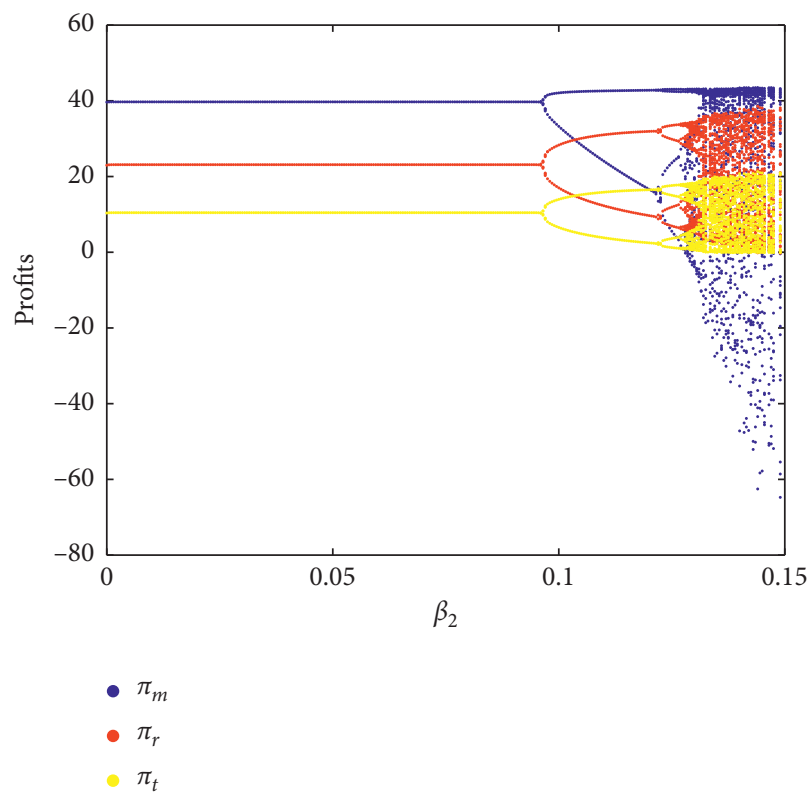

Figure 7: Bifurcation diagram of profits when $\beta_{1}=0.0085$.

Next, we will discuss the Pareto solutions in a dynamic system, First, we set the initial variable $p_{d}(1)=11.5, \omega(1)=8.6$.

In Figures 9-11, we describe the changes of Pareto solutions with $\beta_{2}, \beta_{1}$, and $p$ at different periods. Figure 9 represents the Pareto solutions of the first period of the dynamic system, Figure 10 represents the fourth period, and Figure 11 represents the ninth period. In the initial period, when $\beta_{1}$ ranges from 0 to $0.15, \beta_{2}$ ranges from 0.2 to 0.45 , or $\beta_{1}$ ranges from 0.25 to 0.5 , $p$ ranges from 0 to 20 and 40 to 50 , and there are Pareto solutions between the profit values of the three channels with great probability. Red, yellow, green, and blue are used to represent different regions. It can be seen from Figures 9 and 10 that the pareto solutions increase 


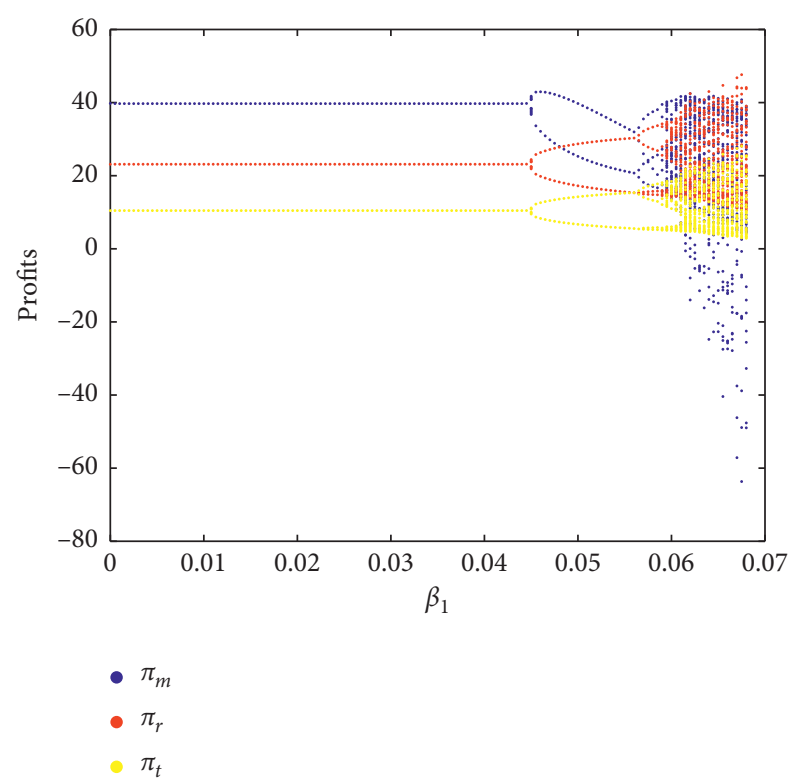

FIgURE 8: Bifurcation diagram of profits when $\beta_{2}=0.015$.

slowly in the four regions. After the ninth period, the number of pareto solutions may increase and stabilize due to the emergence of chaos. According to the results, the decision maker can coordinate the adjustment speed in the recovery system and the retail price of the remanufactured product, so as to avoid the occurrence of the bad solution in the system and ensure the benefit of each member of the supply chain.

The largest Lyapunov exponent presents the system's state. When the largest Lyapunov exponent is smaller than zero, the manufacturers' decision system is stable. When the largest Lyapunov exponent is equal to zero, bifurcation happens. When the largest Lyapunov exponent is bigger than zero, the manufacturers' decision system enters chaos. We draw the largest Lyapunov exponent when $\beta_{1}=0.0085$ and $\beta_{2}=0.015$, respectively, to determine whether the system enters chaos. When the largest Lyapunov exponent is negative, the system is in a stable state; however, when the largest Lyapunov exponent is positive, the system gradually enters the chaotic state. The largest Lyapunov exponent of $\beta_{1}$ and $\beta_{2}$ each time corresponds to a cycle bifurcation point in Figures 3 and 4 when returning to the 0 axis. The largest Lyapunov exponents at $\beta_{1}=0.0085$ and $\beta_{2}=0.015$, respectively, are shown as follows.

As shown in Figures 12 and 13, when the largest Lyapunov exponent returns to 0 first, the system begins to enter the two times of the bifurcation point. When the largest Lyapunov exponent returns to 0 for the third time, the system enters the chaotic state. Similarly, when the largest Lyapunov exponent revolves around zero axis, the system also enters the chaotic state.

The changes of relevant parameters also influence the stability of the whole system, so we verify the effect of the change of retailer price $p$ on the stability of the whole system. We make retailer price change from 0 to 80 and obtain the $3 \mathrm{D}$ stable region with changes of $\beta_{1}, \beta_{2}$, and $p$ as shown in Figure 14 .
It can be seen from Figure 12 that when the value of retailer price exceeds a certain value, the stable region is getting smaller gradually. We also set $p=30, p=35, p=40$, $p=45, p=50$ and draw the stable region with changes of $\beta_{1}$ and $\beta_{2}$ as shown in Figure 15 .

In Figure 15, we can get green border area, blue border area, red border area, purple border area, and yellow border area, respectively, when $p=30, p=35, p=40$, $p=45$, and $p=50$. Observing Figure 15, we can draw the conclusion that is the same as what we can see in Figure 14. It also can be concluded that an appropriate retailer price $p$ should be set to keep the stability of the system. According to the above results, we can clearly determine the stable region of the system. This prevents the system from entering chaos and is conducive to the stability of the market. The findings can help policy makers implement management policies.

The manufacturer is the leader in the closed-loop supply chain, who not only seeks to maximize profits, but also to maintain system stability. And other participants follow the manufacturer's pricing decision. Considering the volatility of the system, if the system starts from the manufacturer's pricing system into chaos, the other participants will accelerate the process of going into chaos. In a word, after the objective factors in the market are determined, the price adjustment of the players in supply chain will have a great impact on the stability of the system. Players need to appropriately adjust their price to cope with the market competition, but once the volatility of the adjustment of players exceeds the reasonable threshold, the market will be in a chaotic state. Therefore, manufacturers can not pursue higher profits or ignore other competitors' strategic behavior and the real-time state of market sales.

\section{Chaos Control}

When the recycling market falls into the unstable state, it will be difficult for corporations to adjust price in a suitable state or obtain higher profit. According to we have stated, once the volatility of the adjustment of players exceeds the reasonable threshold, the market will be in a chaotic state, which is harmful to the whole system. So, in this section, taking the characteristics of the whole decision-making process into consideration, we introduce the delay control method to control the chaos.

The primary idea of the delay control method is to use feedback as an external input after a time delay and ultimately achieve stabilization of unstable periodic orbits of the chaotic attractor.

The core idea of this method is taking part of the information of the output signal of the system into consideration. That is, when making decision for the next period, we think over the decision in this period as well as the decision after a period of time at the same time. Considering other periodic values and adding control factors, the delay control method can effectively eliminate the occurrence of system chaos [52]. Thus, the dynamic adjustment model can be shown as follows: 


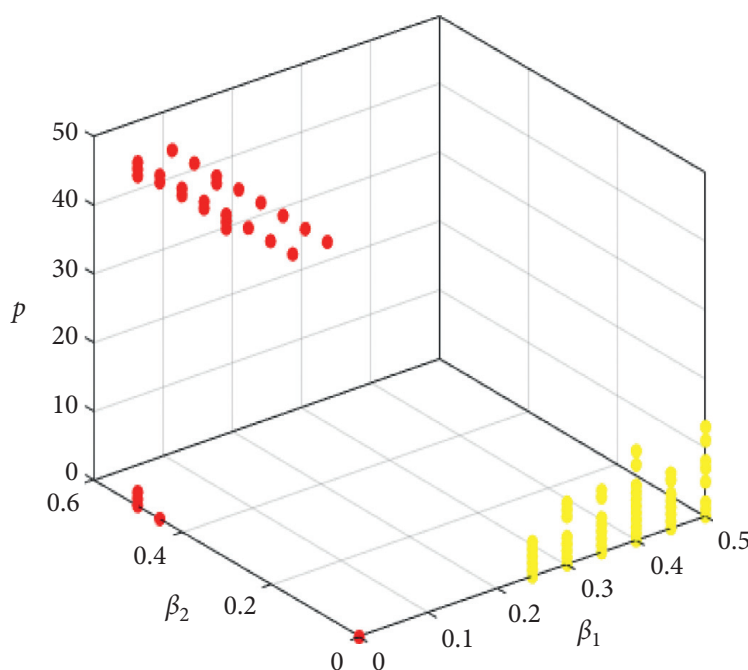

(a)

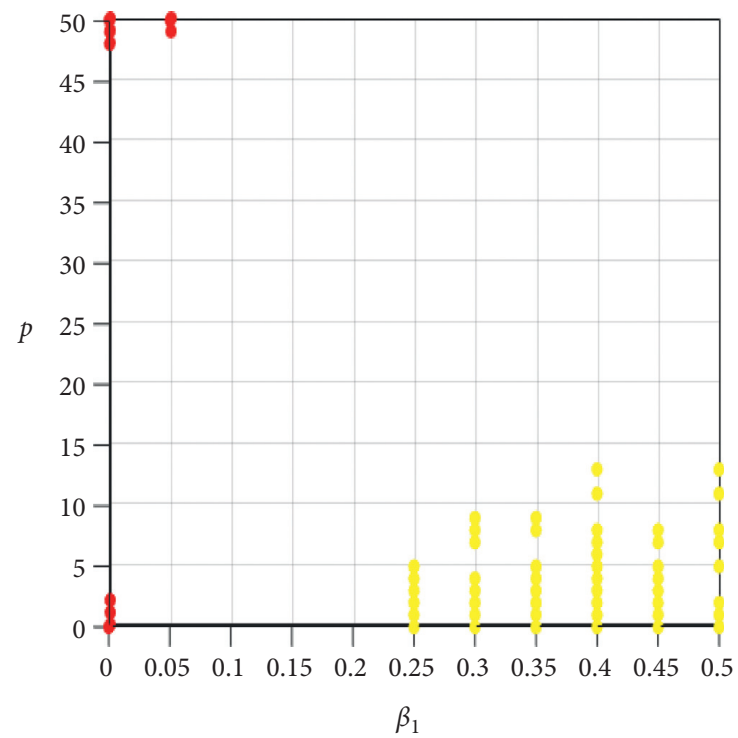

(c)

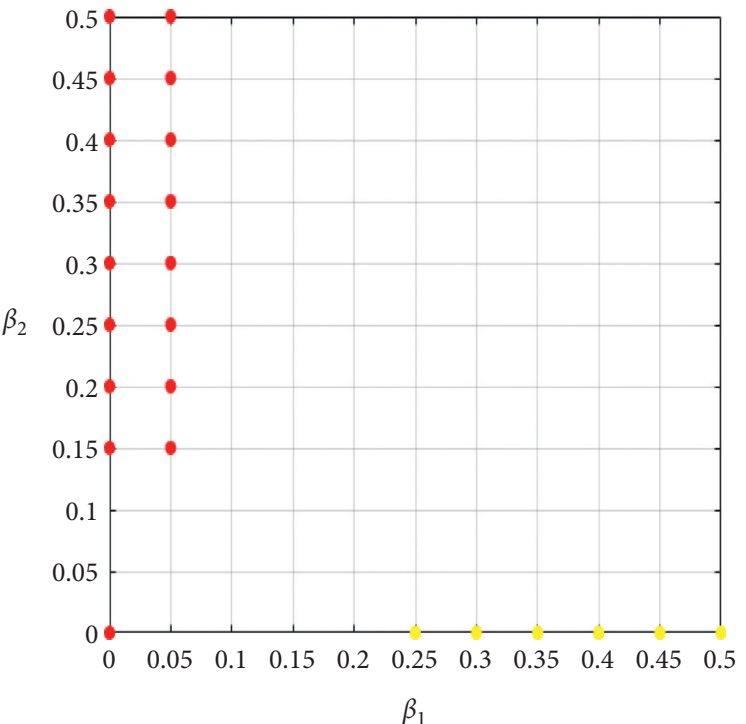

(b)

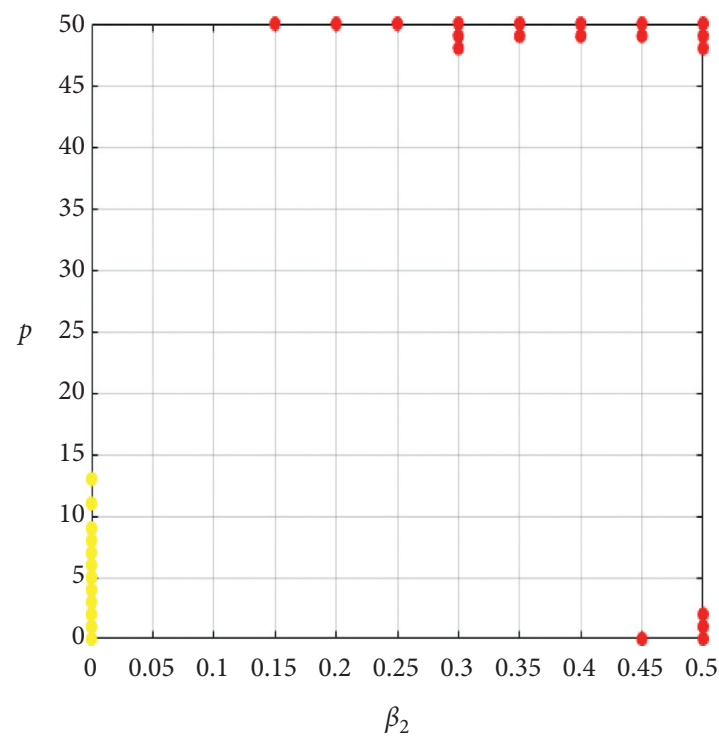

(d)

Figure 9: Pareto solutions at period one. (a) The stereogram of period one, (b) top view of the stereogram, (c) left view of the stereogram, and (d) right view of the stereogram.

$$
\left\{\begin{array}{l}
p_{d}(t+1)=p_{d}(t)+\beta_{1} p_{d}(t) \frac{\partial \Pi_{m}}{\partial p_{d}}+v\left(p_{d}(t)-p_{d}(t+1)\right), \\
\omega(t+1)=\omega(t)+\beta_{2} \omega(t) \frac{\partial \Pi_{m}}{\partial \omega}+v(\omega(t)-\omega(t+1)) .
\end{array}\right.
$$

Formula (18) is the delay strategy equations of the system. Compared with the previous system model, formula (19) adds the difference between the forecast value of the next period and the current period value as the adjustment interval. $v$ is the control parameter, indicating the degree of control over the difference. Then, we set $\beta_{1}=0.03, \beta_{2}=0.1$ and draw bifurcation diagram with increasing $v$ as given in Figure 16.

We show the control of the parameter to the system in Figure 16, where we can see that when $v$ is small, the system is in chaos, and with the control parameter $v$ increasing, the system goes into period doubling and becomes stable at the end. In conclusion, adjusting decision-making method to get over market delay is a good way of system control. Manufacturers can take this method in practice. 


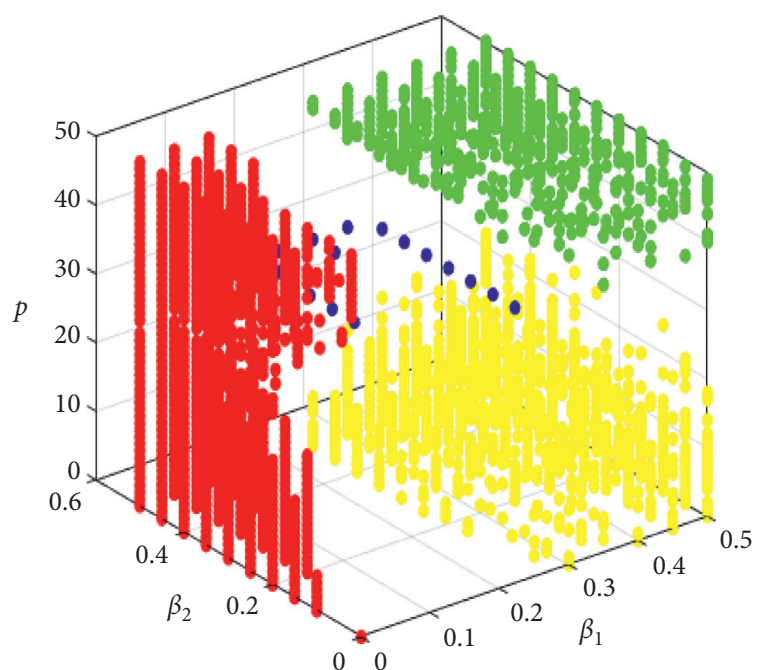

(a)

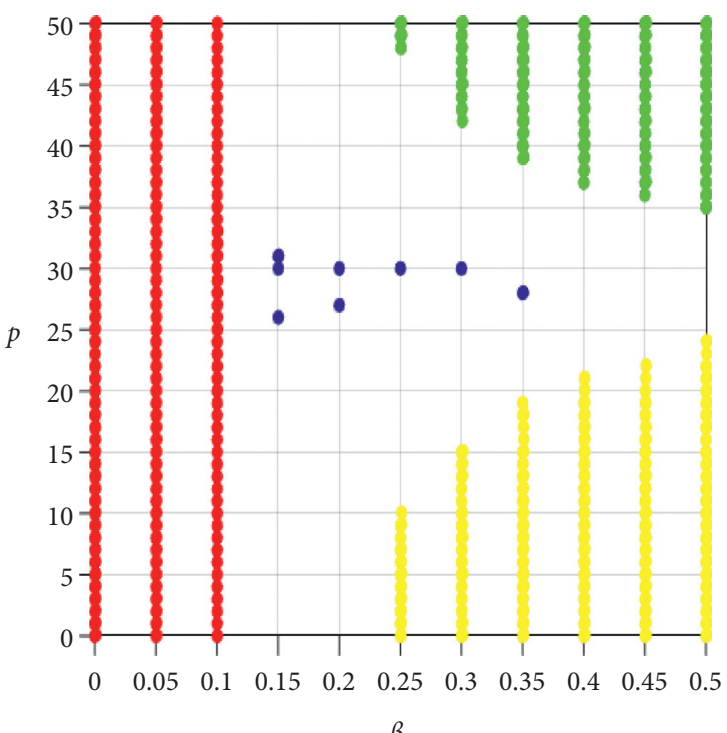

(c)

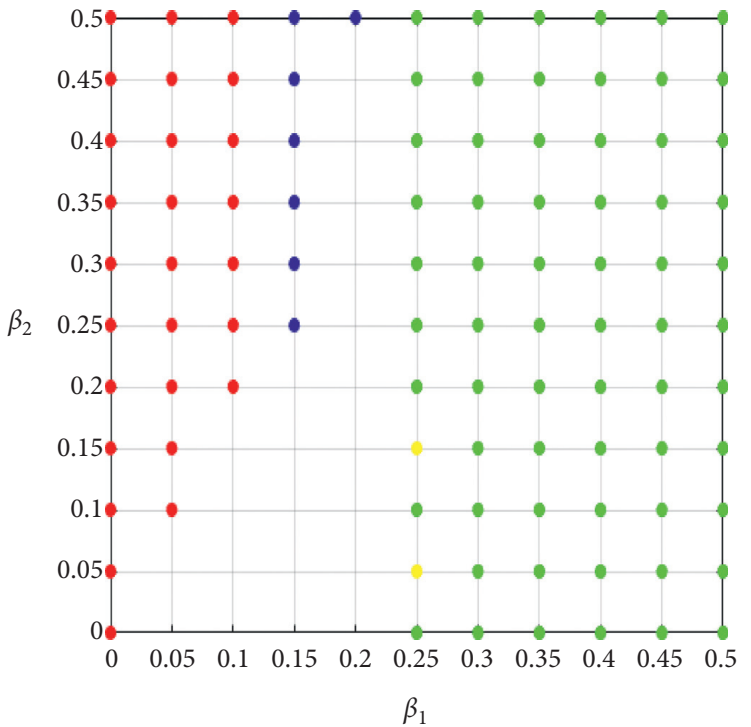

(b)

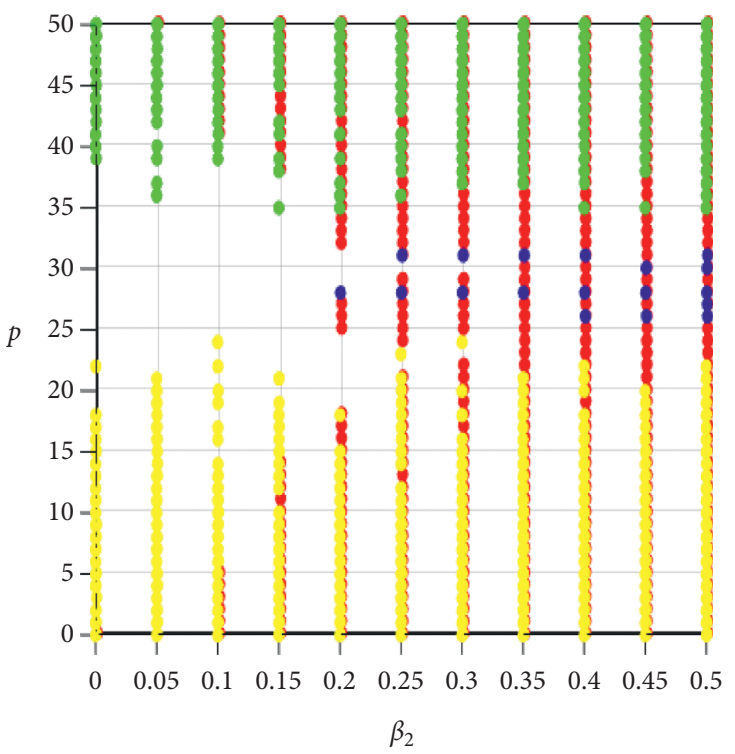

(d)

Figure 10: Pareto solutions at period four. (a) The stereogram of period four, (b) top view of the stereogram, (c) left view of the stereogram, and (d) right view of the stereogram.

In the delay strategy, combined with the difference of $p_{d}$ and $w$ between the actual value in the current cycle and the predicted value in the next cycle, the manufacturers with bounded rationality adjust the value of $p_{d}$ and $w$ in the next cycle by setting certain control factors, so as to avoid large price adjustments and prevent the emergence of market chaos. This can also help manufacturers better control their own recycling prices and make more accurate decisions.

So, we can draw the conclusion that the efficacy is remarkable to control the chaos by the control parameter. To achieve this purpose, the manufacturer, the third-party offline, and online recycler should especially pay attention to the recycling process and services and control the price adjustment speed in the appropriate fields. Consumers in the market should not only focus on the recycling price when choosing the recycling channel.

\section{Extended Model}

In order to encourage companies to carry out larger-scale battery recycling and reduce the pollution of used batteries in society, the government often subsidizes enterprises in a variety of ways. There are two main forms of funding: one is direct cash subsidies, and the other is subsidies based on the number of products recovered by the company.

In order to complete the financial support for enterprises more conveniently, the current government often uses direct 

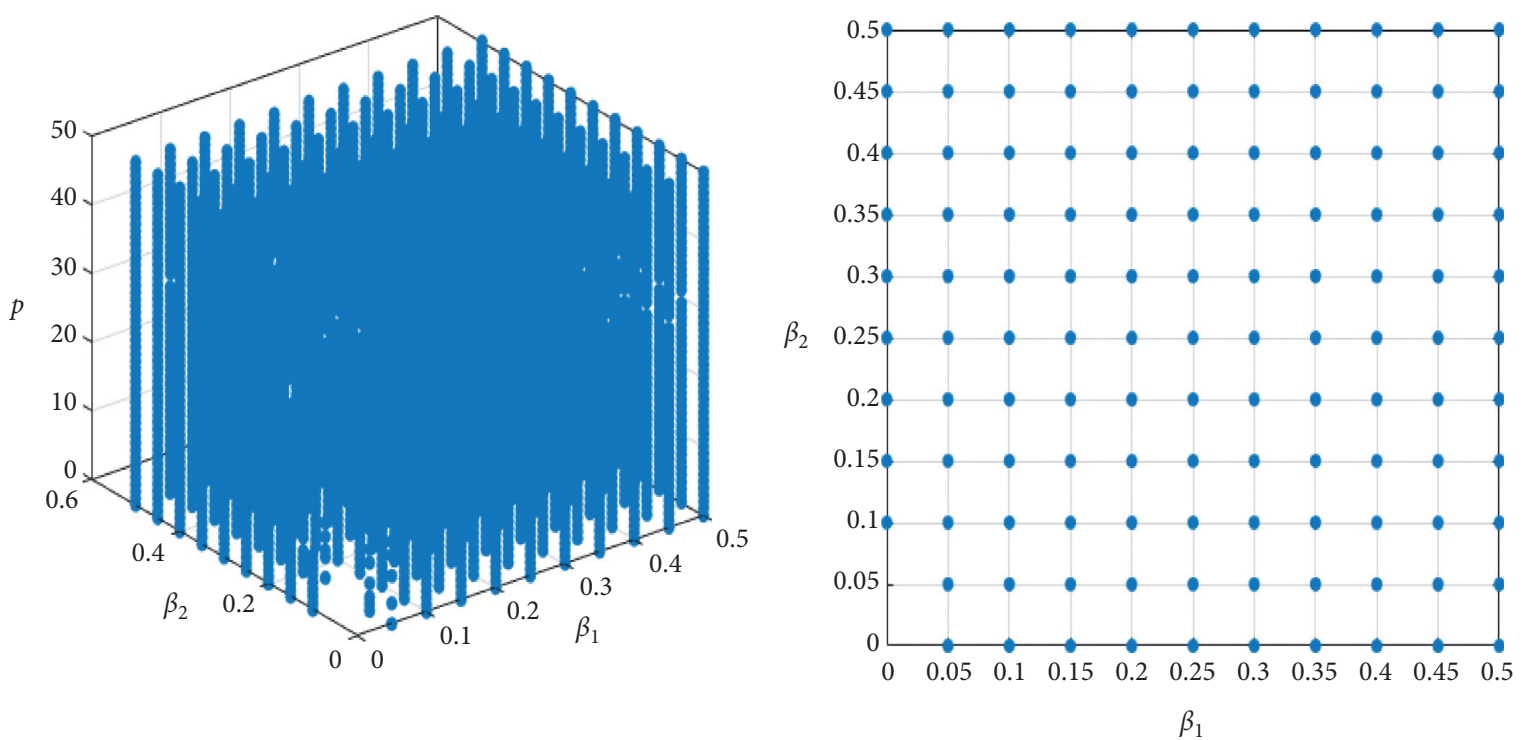

(a)

(b)

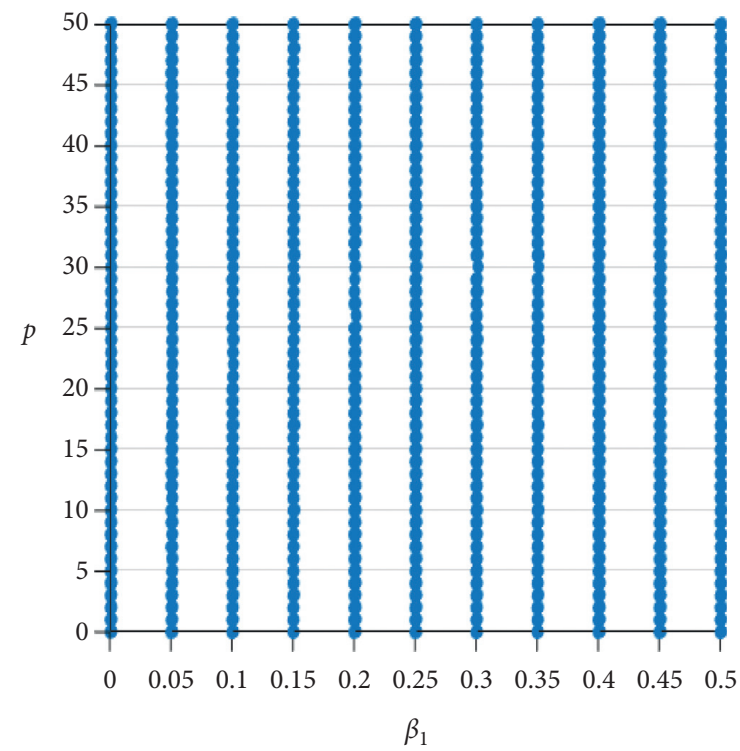

(c)

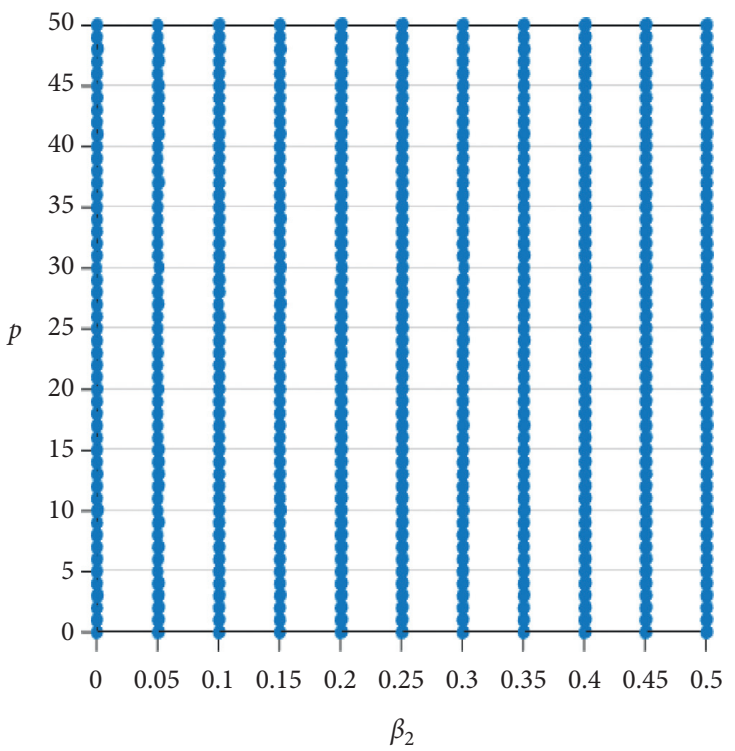

(d)

FIgURe 11: Pareto solutions at period nine. (a) The stereogram of period nine, (b) top view of the stereogram, (c) left view of the stereogram, and (d) right view of the stereogram.

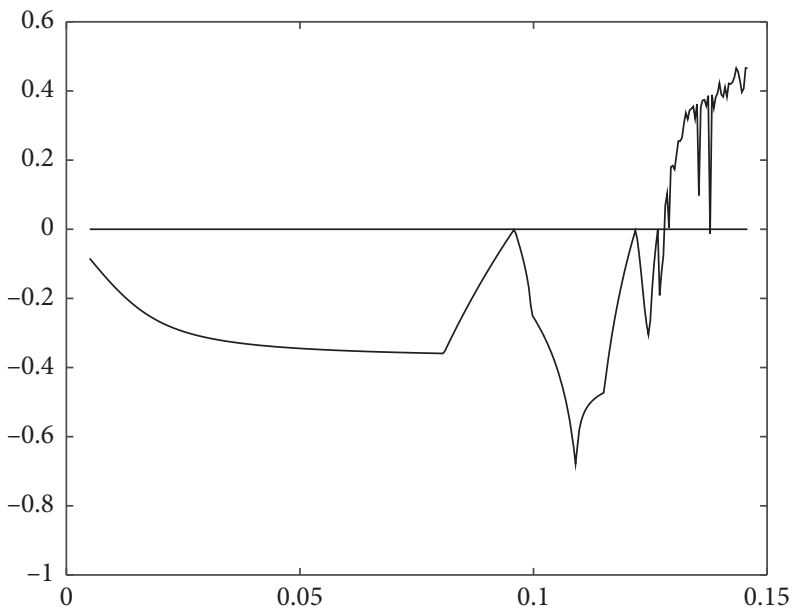

FIGURE 12: The largest Lyapunov exponent when $\beta_{1}=0.0085$. 


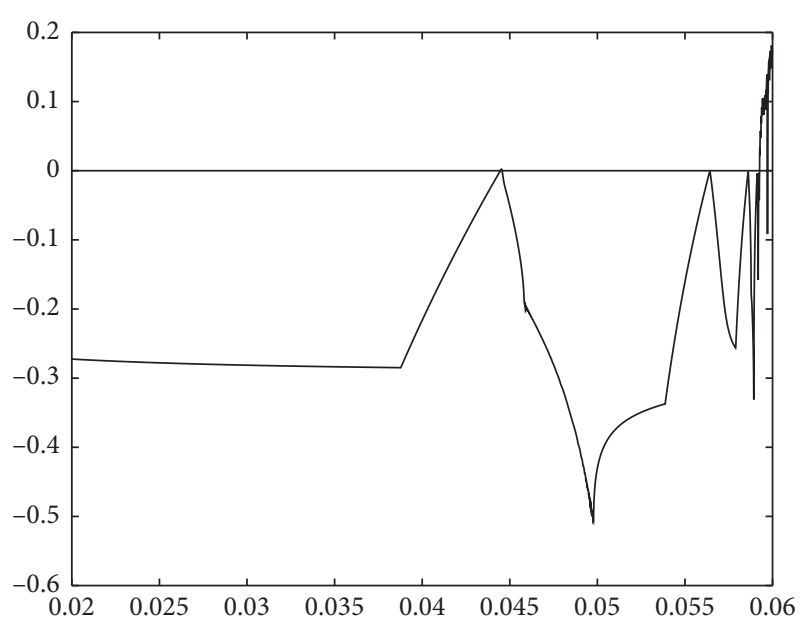

FIGURE 13: The largest Lyapunov exponent when $\beta_{2}=0.015$.

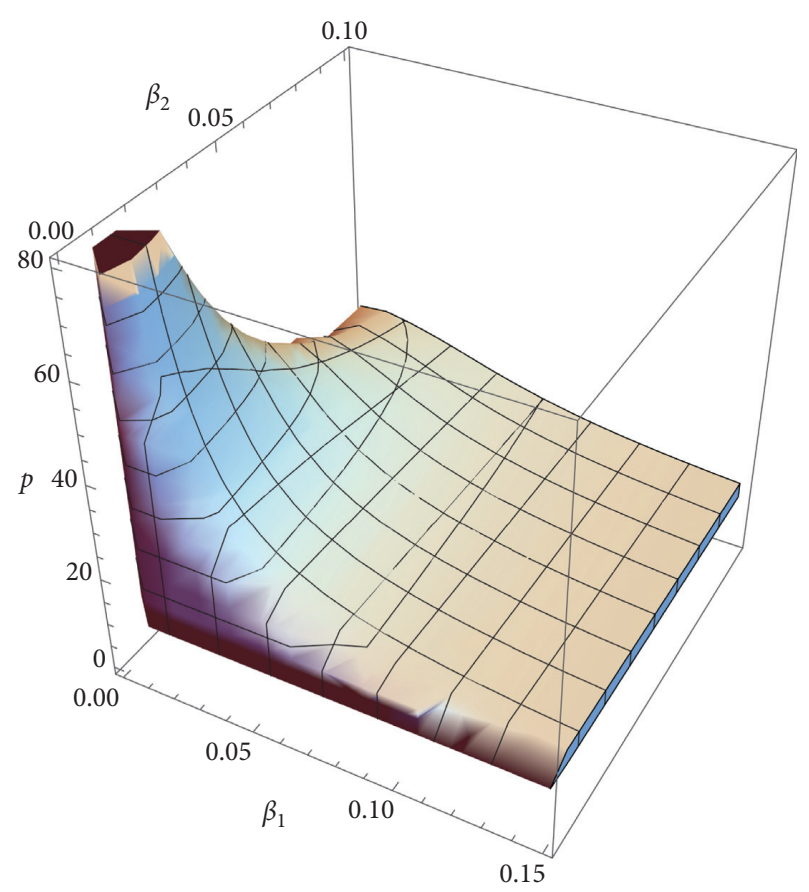

Figure 14: The $3 \mathrm{D}$ stable region with change of $\beta_{1}, \beta_{2}$, and $p$.

cash subsidies to complete the reward work for enterprises to recycle used batteries. This model does not take the recycling amount of enterprises as a reference for subsidies, and each enterprise is subsidized uniformly. Here, we set $M_{1}$ as the subsidy price. The profit model (Model 1) is as follows:

$$
\left\{\begin{array}{l}
\pi_{r}=\left(\omega-p_{r}\right) D_{r}-S_{r}+M_{1}, \\
\pi_{t}=\left(\omega-p_{t}\right) D_{t}-S_{t}+M_{1}, \\
\pi_{m}=\left(p-p_{d}-c\right) D_{d}+(p-\omega-c)\left(D_{r}+D_{t}\right)-S_{d}+M_{1} .
\end{array}\right.
$$

The second method of subsidy is that the government subsidizes the company based on the amount of recycling. The larger the amount of recycling of the enterprise, the higher the government's subsidy. Here, we set the subsidy

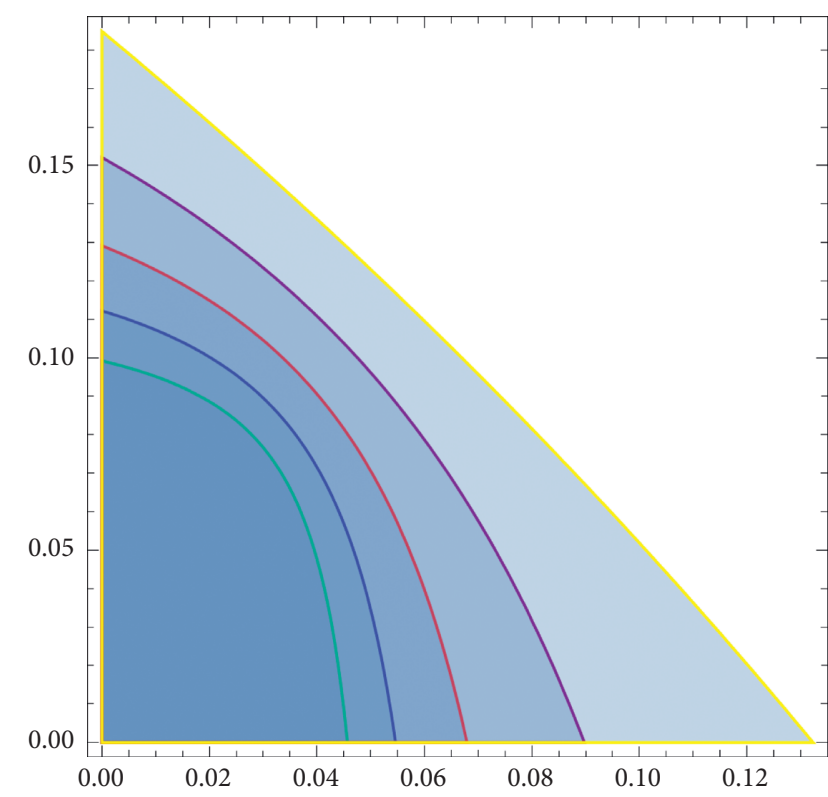

Figure 15: The stable region with change of $\beta_{1}$ and $\beta_{2}$.

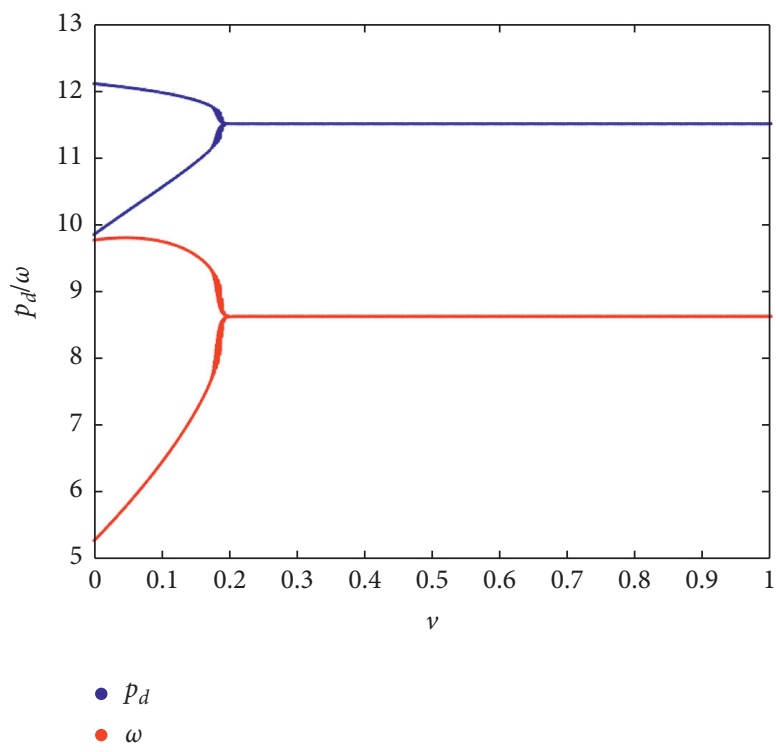

FIGURE 16: Bifurcation diagram with $v$ increasing.

amount per unit of recycled products as $M_{2}$. The profit model (Model 2) is as follows:

$$
\left\{\begin{array}{l}
\pi_{r}=\left(\omega-p_{r}+M_{2}\right) D_{r}-S_{r}, \\
\pi_{t}=\left(\omega-p_{t}+M_{2}\right) D_{t}-S_{t}, \\
\pi_{m}=\left(p-p_{d}-c+M_{2}\right) D_{d}+\left(p-\omega-c+M_{2}\right)\left(D_{r}+D_{t}\right)-S_{d} .
\end{array}\right.
$$

Next, we will discuss the changes in the profits of the three recycling entities under the direct subsidy $M_{1}$ and the price subsidy $M_{2}$.

Figure 17 shows the selection range of the optimal subsidy model for the three recycling entities under the changes of government direct cash subsidies and price 


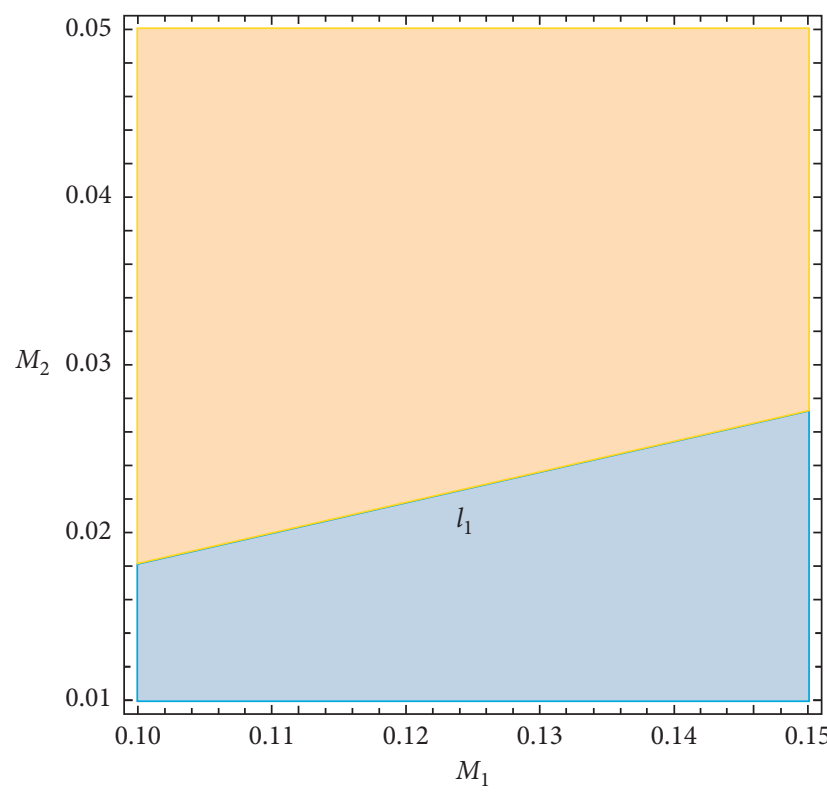

Model 1

Model 2

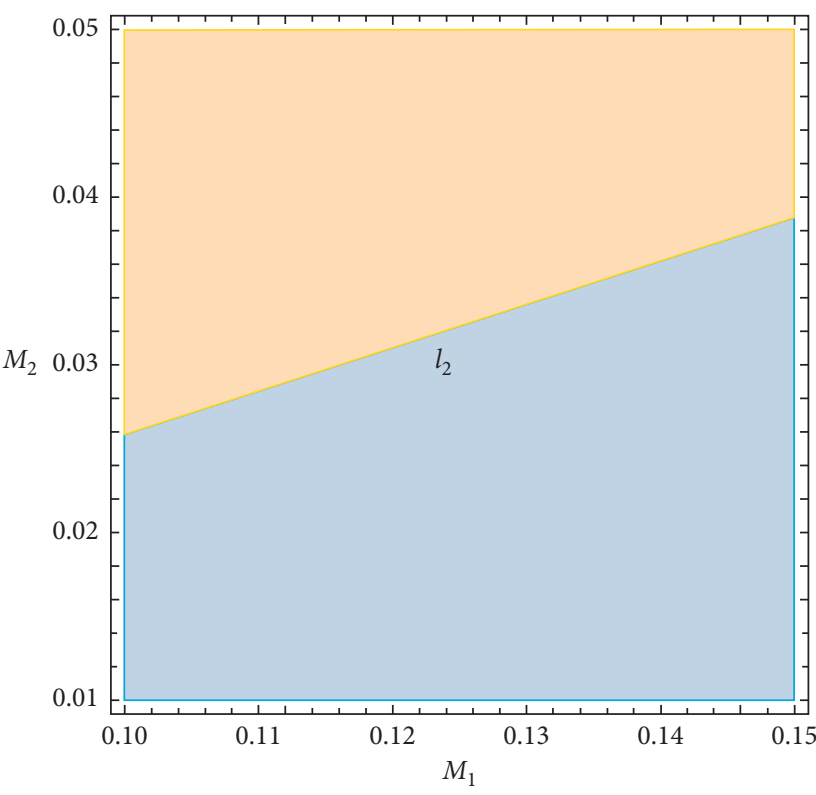

Model 1

Model 2

(a)

(b)

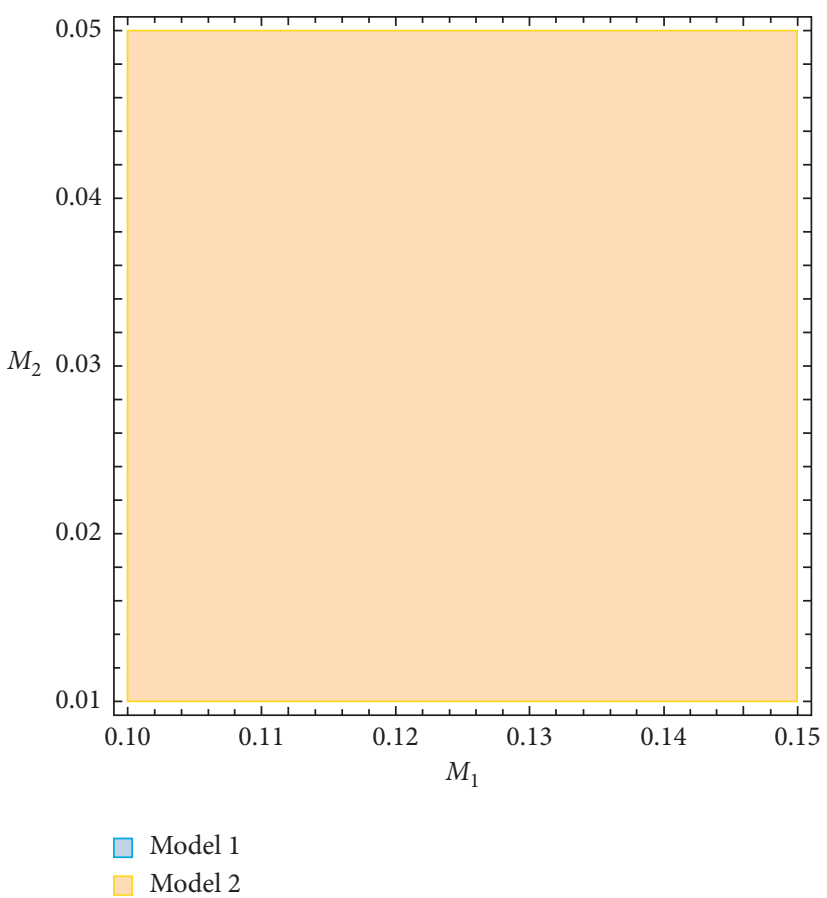

(c)

FIGURE 17: Selection of subsidy models with $M_{1} \& M_{2}$ increasing. (a) Third-party offline recycler, (b) third-party online recycler, and (c) manufacturer.

subsidies. Here, Figure 17(a) shows the third-party offline recycler's model selection. Figure 17(b) shows the third-party online recycler's model selection, and Figure 17(c) shows the manufacturer's model selection. It can be seen from the figure that when the government's price subsidy $M_{2}$ is lower than $l_{1}$, third-party offline recyclers are more inclined to choose direct cash subsidies to increase the company's profits. When the government's price subsidy $M_{2}$ is higher than $l_{1}$, the third-party offline recyclers will choose the price subsidy model. In the same way, we can see the best choice of third-party online recycler. But no matter how the direct cash subsidy changes, manufacturers will always choose the price subsidy model. This is because the 
manufacturer's recycling volume is relatively large. Compared with direct cash subsidies, price subsidies can alleviate more economic pressure for them.

\section{Conclusion}

In this paper, we study the game between the traditional recycling channels and the online recovery platform with the upsurge of "Internet plus" recycling platform in recent years. By learning relevant literature and using complex dynamics theory, we build a supply chain recycling system consisting of a manufacturer, a third-party online recycler, a thirdparty offline recycler, and consumers. Then, through numerical simulation, the dynamic changes of the stable region, Pareto solutions, recovery price, and profit in the dynamic system are studied and analyzed. In the end, we use the adaptive method to control the chaotic state of this model. The conclusion of our study is drawn as follows:

(1) The manufacturer is the leader in the game of supply chain system and is of bounded rationality. In a longterm dynamic repeated game process, the manufacturer should control the adjustment speed of recycling price and keep it within the threshold, so that the market can maintain a stable state. Otherwise, excessive adjustment of recycling prices will prevent the manufacturer from making accurate price decisions, which also leads to instability in the decisions of other recycling companies. This will mess up the recycling market.

(2) The third-party online recycler and the third-party offline recycler follow the manufacturer's decision to make a price. The third-party online recycler and the third-party offline recycler should always pay attention to the speed of price adjustment of the manufacturer. Because when the manufacturer's recovery price fluctuates, the recovery price of the third-party online recycler and the third-party offline recycler will also fluctuate sharply. This will lead to a vicious circle in the market. Therefore, the thirdparty online recycler and offline recycler should make hedging plans in advance to reduce the impact on themselves.

(3) As the manufacturer's retail price increases, the stable area of the market becomes smaller. This shows that the increase in the manufacturer's retail price will lead to a decrease in consumers' purchasing expectations. Therefore, the size of the entire recycling system will also shrink, leading to instability. Therefore, manufacturers can make targeted adjustments to the stability of the market by setting appropriate selling prices, so as to benefit themselves in the process of market changes. At the same time, third-party online recyclers and third-party offline recyclers should be alert to changes in manufacturers' selling prices.

(4) In the initial period of dynamic system evolution, the recovery system has regional Pareto solutions, and with the progress of the period, the relevant region is expanding. In order to achieve Pareto optimal profit for each member of the supply chain, the adjustment speed of the dynamic system and the retail price of the remanufactured products should be kept within a certain range, so as to avoid the occurrence of bad solutions.

(5) Adjusting the decision method to control the chaos is considered, and it has a good control of the chaos of the system. When the manufacturer considers the difference of recycling price between the current period and the next period, it will effectively avoid market instability caused by excessive price adjustments. When chaos occurs in the system, decisionmakers can adopt delay control strategy to keep the market stable.

(6) With the changes in government price subsidies, the optimal model selection of third-party recyclers will gradually shift from the direct cash subsidy model to the price subsidy model. Due to the large amount of recycling, manufacturers will always choose the price subsidy model.

This paper examines the long-term repeated game behavior of a reverse supply chain, which contains two recyclers and one manufacturer. This paper has certain reference value for the supply chain that has three channels of third-party online recyclers, third-party offline recyclers, and manufacturers' direct recycling. At the same time, this paper has some research value in the stability and control of dynamic systems in closed-loop supply chain. The conclusion shows that the adjustment speed of the recycling price has the most significant impact on the recycle market. In reality, players cannot get full information about the market. Adopting bounded rational decision can help enterprises obtain the optimal solution after repeated games. Note that the players should adopt appropriate adjustment speed to get the optimal solutions early and maintain the stability of the system. However, there is some limitation in our work. For example, in order to simplify the model, we assume that price sensitivity coefficient and price cross influence coefficient are equal, which may not correspond to reality. We leave this for future. With the development of remanufactured product channels, future research may not only recycle products through third-party recyclers. Manufacturers may increase profits by selling through third-party recyclers, thus forming a more interactive supply chain structure.

\section{Appendix}

In equation (13), let $\left(\partial \pi_{m} / \partial p_{d}\right)=0,\left(\partial \pi_{m} / \partial \omega\right)=0$, and we get at most four fixed points. As we have stated, we get the unique equilibrium point of the model as follows:

$$
\left(p_{d}^{*}, \omega^{*}\right)
$$

where 


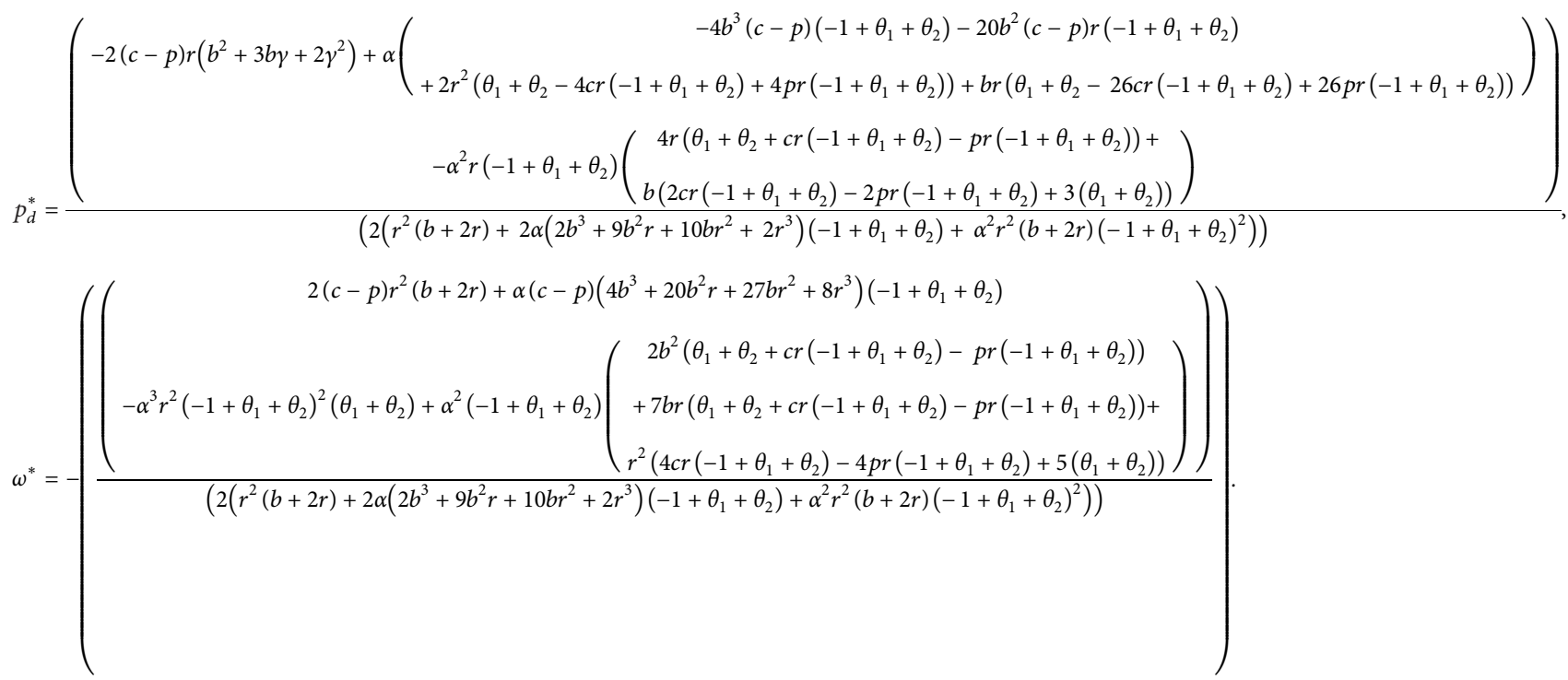

\section{Data Availability}

The data used to support the findings of this study are available from the corresponding author upon request.

\section{Conflicts of Interest}

The authors declare no conflicts of interest.

\section{References}

[1] China Household Electrical Appliance Research Institute, "White paper 2016 of recycling and comprehensive utilization of waste electrical and electronic products in China," 2016, http://www.weee-epr.org.

[2] National Statistical Bureau, China Statistical Yearbook, China Statistics Press, Beijing, China, 2017.

[3] R. C. Savaskan, S. Bhattacharya, and L. N. Van Wassenhove, "Closed-loop supply chain models with product remanufacturing," Management Science, vol. 50, no. 2, pp. 239-252, 2004.

[4] The State Council the People's Republic of China, "Guiding opinions of the state council on promoting "internet plus"” action, 2015, https://www.gov.cn/zhengce/content/2015-07/ 04/content_10002.htm.

[5] The State Council the People's Republic of China, "Notice of the national development and reform commission on printing and distributing the circular economy promotion plan in 2015," 2015, http://www.gov.cn/xinwen/2015-04/20/content_2849620.htm.

[6] X. Dou, "Love traditional recycling industry "internet plus"” Enterprise Management Innovation, vol. 10, pp. 107-109, 2016.

[7] K. D. Cattani, W. G. Gilland, and J. M. Swaminathan, "Coordinating traditional and internet supply chains," International Series in Operations Research \& Management Science, vol. 74, pp. 643-677, 2004.

[8] W.-M. Ma, Z. Zhao, and H. Ke, "Dual-channel closed-loop supply chain with government consumption-subsidy," European Journal of Operational Research, vol. 226, no. 2, pp. 221-227, 2013.

[9] L. Sun and J. Ma, "Study and simulation on dynamics of a risk-averse supply chain pricing model with dual-channel and incomplete information," International Journal of Bifurcation and Chaos, vol. 26, no. 9, Article ID 1650146, 2016.

[10] J. Ma and H. Wang, "Complexity analysis of dynamic noncooperative game models for closed-loop supply chain with product recovery," Applied Mathematical Modelling, vol. 38, no. 23, pp. 5562-5572, 2014.

[11] B. C. Giri, A. Chakraborty, and T. Maiti, "Pricing and return product collection decisions in a closed-loop supply chain with dual-channel in both forward and reverse logistics," Journal of Manufacturing Systems, vol. 42, pp. 104-123, 2017.

[12] X. Hong, X. Cao, Y. Gong, and W. Chen, "Quality information acquisition and disclosure with green manufacturing in a closed-loop supply chain," International Journal of Production Economics, vol. 232, Article ID 107997, 2021.

[13] S. Zhang and Q. Meng, "Electronics closed-loop supply chain value co-creation considering cross-shareholding," Journal of Cleaner Production, vol. 278, Article ID 123878, 2021.

[14] S. Wood, I. Watson, and C. Teller, "Pricing in online fashion retailing: implications for research and practice," Journal of Marketing Management, 2021.

[15] J. Ma, Y. Hou, W. Yang, and Y. Tian, "A time-based pricing game in a competitive vehicle market regarding the intervention of carbon emission reduction," Energy Policy, vol. 142, Article ID 111440, 2020.

[16] S. Gan, I. Pujawan, Suparno, and B. Widodo, "Pricing decision for new and remanufactured product in a closed-loop supply chain with separate sales-channel," International Journal of Production Economics, vol. 190, pp. 120-132, 2016.

[17] J. Ma, W. Lou, and Y. Tian, "Bullwhip effect and complexity analysis in a multi-channel supply chain considering price game with discount sensitivity," International Journal of Production Research, vol. 57, no. 17, pp. 5432-5452, 2019.

[18] N. M. Modak, N. Mohan, S. Panda, and S. S. Sana, "Analyzing structure of two-echelon closed-loop supply chain for pricing, quality and recycling management," Journal of Cleaner Production, vol. 171, pp. 512-528, 2017.

[19] X. Hong, K. Govindan, L. Xu, and P. Du, "Quantity and collection decisions in a closed-loop supply chain with technology licensing," European Journal of Operational Research, vol. 256, no. 3, pp. 820-829, 2017. 
[20] H. Sun, J. Hu, and L. Wang, "Pricing strategies and collection mode of two-period closed-loop supply chain based on price reference effect," Jisuanji Jicheng Zhizao Xitong/Computer Integrated Manufacturing Systems, vol. 22, no. 12, pp. 28752887, 2016.

[21] B. Bao, J. Ma, and M. Goh, "Short-and long-term repeated game behaviours of two parallel supply chains based on government subsidy in the vehicle market," International Journal of Production Research, vol. 58, no. 24, pp. 7507-7530, 2020.

[22] L. Xie, J. Ma, and M. Goh, "Supply chain coordination in the presence of uncertain yield and demand," International Journal of Production Research, vol. 59, no. 14, pp. 1-17, 2020.

[23] J. Ma and W. Xie, "Application and research on the complex dynamics behaviour under price-discount promotion policy in inventory control system," International Journal of Logistics Research and Applications, vol. 19, no. 6, pp. 520-536, 2016.

[24] H. Sander, "Competitive pricing despite search costs when lower price signals quality," Economic Theory, vol. 71, pp. 317-339, 2021.

[25] N. M. Modak, N. Modak, S. Panda, and S. S. Sanad, "Analyzing structure of two-echelon closed-loop supply chain for pricing, quality and recycling management," Journal of Cleaner Production, vol. 171, pp. 512-528, 2018.

[26] I. E. Nielsen, S. Majumder, S. S. Sana, and S. Saha, "Comparative analysis of government incentives and game structures on single and two-period green supply chain," Journal of Cleaner Production, vol. 235, pp. 1371-1398, 2019.

[27] Y. Li, Q. Deng, C. Zhou, and L. Feng, "Environmental governance strategies in a two-echelon supply chain with tax and subsidy interactions," Annals of Operations Research, vol. 290, no. 2020, pp. 439-462, 2018.

[28] T. Ji, X. Xu, X. Yan, and Y. Yu, "The production decisions and cap setting with wholesale price and revenue sharing contracts under cap-and-trade regulation," International Journal of Production Research, vol. 58, no. 2020, pp. 128-147, 2019.

[29] G. Raz and A. Ovchinnikov, "Coordinating pricing and supply of public interest goods using government rebates and subsidies," IEEE Transactions on Engineering Management, vol. 62, no. 1, pp. 65-79, 2015.

[30] X. Li and Y. Li, "On green market segmentation under subsidy regulation," Supply Chain Management: An International Journal, vol. 22, no. 3, pp. 284-294, 2017.

[31] X. Long, T. Shu, S. Chen, S. Wang, K. K. Lai, and Y. Yang, "Strategy analysis of recycling and remanufacturing by remanufacturers in closed-loop supply chain," Sustainability, vol. 9, no. 10, Article ID 1818, 2017.

[32] P. De Giovanni and G. Zaccour, "A two-period game of a closed-loop supply chain," European Journal of Operational Research, vol. 232, no. 1, pp. 22-40, 2014.

[33] J. Mohammad, M. K. Zanjani, and M. Gendreau, “Accelerating benders decomposition for closed-loop supply chain network design: case of used durable products with different quality levels," European Journal of Operational Research, vol. 251, no. 3, pp. 830-845, 2016.

[34] L. Zhou, M. M. Naim, and S. M. Disney, "The impact of product returns and remanufacturing uncertainties on the dynamic performance of a multi-echelon closed-loop supply chain," International Journal of Production Economics, vol. 183, pp. 487-502, 2016.

[35] V. V. Agrawal, A. Atasu, and K. van Ittersum, "Remanufacturing, third-party competition, and consumers' perceived value of new products," Management Science, vol. 61, no. 1, pp. 60-72, 2015.
[36] S. S. Sana, "A structural mathematical model on two echelon supply chain system," Annals of Operations Research, pp. 1-29, 2021.

[37] A. A. Taleizadeh, M. Noori-Daryan, and S. S. Sana, "Manufacturing and selling tactics for a green supply chain under a green cost sharing and a refund agreement," Journal of Modelling in Management, vol. 15, no. 4, pp. 1419-1450, 2020.

[38] S. S. Sana, "Price competition between green and non green products under corporate social responsible firm," Journal of Retailing and Consumer Services, vol. 55, Article ID 102118, 2020.

[39] A. Atasu, L. B. Toktay, and L. N. Van Wassenhove, "How collection cost structure drives a manufacturer's reverse channel choice," Production and Operations Management, vol. 22, pp. 1089-1102, 2013.

[40] L. Feng, K. Govindan, and C. Li, "Strategic planning: design and coordination for dual-recycling channel reverse supply chain considering consumer behavior," European Journal of Operational Research, vol. 260, no. 2, pp. 601-612, 2017.

[41] L. Xie and J. Ma, "Study the complexity and control of the recycling-supply chain of China's color TVs market based on the government subsidy," Communications in Nonlinear Science and Numerical Simulation, vol. 38, pp. 102-116, 2016.

[42] J. Ma and L. Sun, "Complexity analysis about nonlinear mixed oligopolies game based on production cooperation," IEEE Transactions on Control Systems Technology, vol. 26, no. 4, pp. 1532-1539, 2018.

[43] T. Maiti and B. C. Giri, "Two-way product recovery in a closed-loop supply chain with variable markup under price and quality dependent demand," International Journal of Production Economics, vol. 183, pp. 259-272, 2016.

[44] J. Ma and L. Xie, "The comparison and complex analysis on dual-channel supply chain under different channel power structures and uncertain demand," Nonlinear Dynamics, vol. 83, no. 3, pp. 1379-1393, 2016.

[45] T. Xu and J. Ma, "Feed-in tariff or tax-rebate regulation? dynamic decision model for the solar photovoltaic supply chain," Applied Mathematical Modelling, vol. 89, pp. 1106-1123, 2021.

[46] J. H. Ma, Y. M. Hou, Z. X. Wang, and W. H. Yang, "Pricing strategy and coordination of automobile manufacturers based on government intervention and carbon emission reduction," Energy Policy, vol. 148, no. 1, Article ID 111919, 2021.

[47] X. Su, H. L. Liu, and S. Q. Hou, "The trilateral evolutionary game of agri-food quality in farmer-supermarket direct purchase: a simulation approach," Complexity, vol. 2, Article ID 684185, 2018.

[48] X. Su, S. S. Duan, and H. L. Liu, "Evolutionary games in the agricultural product quality and safety information system: a multiagent simulation approach," Complexity, vol. 2, Article ID 185497, 2018.

[49] Q. He, N. Wang, Z. Yang, Z. He, and B. Jiang, "Competitive collection under channel inconvenience in closed-loop supply chain," European Journal of Operational Research, vol. 275, no. 1, pp. 155-166, 2019.

[50] N. Wang, Q. He, and B. Jiang, "Hybrid closed-loop supply chains with competition in recycling and product markets," International Journal of Production Economics, vol. 217, pp. 246-258, 2019.

[51] K. Rahmani and M. Yavari, "Pricing policies for a dual-channel green supply chain under demand disruptions," Computers \& Industrial Engineering, vol. 127, pp. 493-510, 2019.

[52] D. Dai, F. Si, and J. Wang, "Stability and complexity analysis of a dual-channel closed-loop supply chain with delayed decision under government intervention," Entropy, vol. 19, no. 11, p. 577, 2017. 